\title{
Study of Occupant Exposure of Drivers and Commuters with Temporal Variation of In-Vehicle Pollutant Concentrations in Public Transport Buses Operating on Alternative Diesel Fuels
}

\author{
Akhil Kadiyala*, Ashok Kumar and Abhilash Vijayan
}

Department of Civil Engineering, University of Toledo, 2801 W. Bancroft St., Toledo, Ohio 43606, USA

\begin{abstract}
The objective of this study is to determine the occupant/driver exposure in public transport buses running on biodiesel (B20) and ultra low sulfur diesel (ULSD) buses in the city of Toledo, Ohio. This paper also presents a protocol used for carrying out an experimental study involving continuous monitoring of real-time in-vehicle pollutant concentrations. In-vehicle concentrations of six air pollutants including carbon dioxide $\left(\mathrm{CO}_{2}\right)$, carbon monoxide $(\mathrm{CO})$, nitric oxide (NO), nitrogen dioxide $\left(\mathrm{NO}_{2}\right)$, sulfur dioxide $\left(\mathrm{SO}_{2}\right)$, and particulate matter less than 2.5 micrometer $\left(\mathrm{PM}_{2.5}\right)$, in addition to two important comfort parameters- temperature and relative humidity are monitored in the two selected buses. This study provides new insights about the indoor environment of public transport buses operating on biodiesel fuels.

Results indicate the average 8-hr. exposure of $\mathrm{B} 20$ occupants to $\mathrm{CO}_{2}, \mathrm{CO}, \mathrm{NO}, \mathrm{NO}_{2}, \mathrm{SO}_{2}$, and $\mathrm{PM}_{2.5}$ to be $559.67 \mathrm{ppm}( \pm$ $45.01), 18.33 \mathrm{ppm}( \pm 9.23), 5.23 \mathrm{ppm}( \pm 4.49), 0.13 \mathrm{ppm}( \pm 0.05), 0.13 \mathrm{ppm}( \pm 0.01)$, and $13.75 \mu \mathrm{g} / \mathrm{m}^{3}( \pm 4.24) \mathrm{respec}-$ tively while for ULSD bus occupants the average exposures are $632.20 \mathrm{ppm}( \pm 102.70), 8.08 \mathrm{ppm}( \pm 1.41), 0.73 \mathrm{ppm}( \pm$ $0.21), 0.09 \mathrm{ppm}( \pm 0.06), 0.39 \mathrm{ppm}( \pm 0.04)$, and $13.33 \mu \mathrm{g} / \mathrm{m}^{3}( \pm 5.49)$. It was also observed that the mean 8 -hour exposure to carbon dioxide and sulfur dioxide were significantly higher inside ULSD buses as compared to B20 fueled buses, while the carbon monoxide and nitric oxide concentrations were higher inside B20 buses. Exposure to nitrogen dioxide and particulate matter are statistically similar for both the buses. None of the pollutants except CO exceeded the TWA limits.
\end{abstract}

Keywords: Indoor Air Quality, Monitoring Indoor Pollutants, Vehicular Microenvironment, Driver and Passenger Exposure, Alternative Fuels, Biodiesel, Ultra Low Sulfur Diesel.

\section{INTRODUCTION}

A careful study of the indoor air quality in different microenvironments is very important in understanding the levels of exposure to different pollutants in different places, especially since people spend about $87 \%$ of their time indoors and $5-6 \%$ of their daily time commuting, mostly between their workplace and their residence [1]. Several studies have been reported in the literature to study the indoor air quality in a transportation microenvironment. Zhang et al. [2] monitored the emissions of benzene, toluene, xylene, and formaldehyde in parked vehicles in the underground parking that represent the passenger exposure to emissions from materials in passenger cabins. It was also observed that the emissions monitored were found to be higher in new vehicles as compared to older vehicles. Chan et al. [3] studied the exposure of passengers to particulate matter (PM) and carbon monoxides $(\mathrm{CO})$ in four different public commuting modes - taxi, subway, air conditioned bus, and non-air conditioned bus in urban routes and found that the passenger exposure was influenced by commuting mode selected by the passenger. Similar observations were made by Chan et al. [4] where the pollutant studied was VOC. Diapouli et al. [5] studied exposure to particulate matter less than $10 \mathrm{mi}-$ crometer $\left(\mathrm{PM}_{10}\right)$ and ultra fine particles and observed that the

*Address correspondence to this author at the Department of Civil Engineering, University of Toledo, $2801 \mathrm{~W}$. Bancroft St., Toledo, Ohio 43606, USA; Tel: (419) 530-8120; Fax: (419) 530-8116; E-mail: akhilkadiyala@gmail.com exposure was higher in areas of heavy traffic and during the peak hours. Chan and Liu [6] studied the exposure to carbon monoxide in three different commuting modes - bus, minibus, and taxi and observed that the exposure apart from being influenced by heavy traffic and street configuration was increased by 2-3 times in tunnel microenvironment as compared to urban and sub-urban roads. Gulliver and Briggs [7] studied the exposure to $\mathrm{PM}_{1.0}, \mathrm{PM}_{2.5}$, and $\mathrm{PM}_{10}$, during walking and in-car travel and found that exposures were higher in case of cars as compared to those walking. Gomez-Perales et al. [8] addressed the exposure to $\mathrm{PM}_{2.5}$, carbon monoxide, benzene, and chemical composition of $\mathrm{PM}_{2.5}$ on three different transportation modes - minibus, bus, and metro, and observed the minibus concentrations to be higher during the morning peak hours. Bremauntz and Ashmore [9] studied exposure to carbon monoxide levels in different commuting modes that included bus, collective taxi, minibus, auto, and metro, and observed that there is statistically significant difference in $\mathrm{CO}$ concentrations in different modes. Clifford et al. [10] studied the driver exposure to carbon monoxide and observed surrounding vehicles to strongly affect the vehicular CO levels. Chan et al. [11] studied the exposure to $\mathrm{PM}_{10}$ and $\mathrm{PM}_{2.5}$ over 8 different transportation modes and observed in-vehicle particulate matter exposure levels to be dependent on the choice of transport microenvironment and mode of ventilation adopted. Kuo et al. [12] studied exposure to VOC on six main roads and observed commuter exposure to vary with route selected. Chan [13] studied exposure to $\mathrm{CO}$ and $\mathrm{CO}_{2}$ in different buses inside and outside using portable monitors. The study observed in-vehicle pol- 


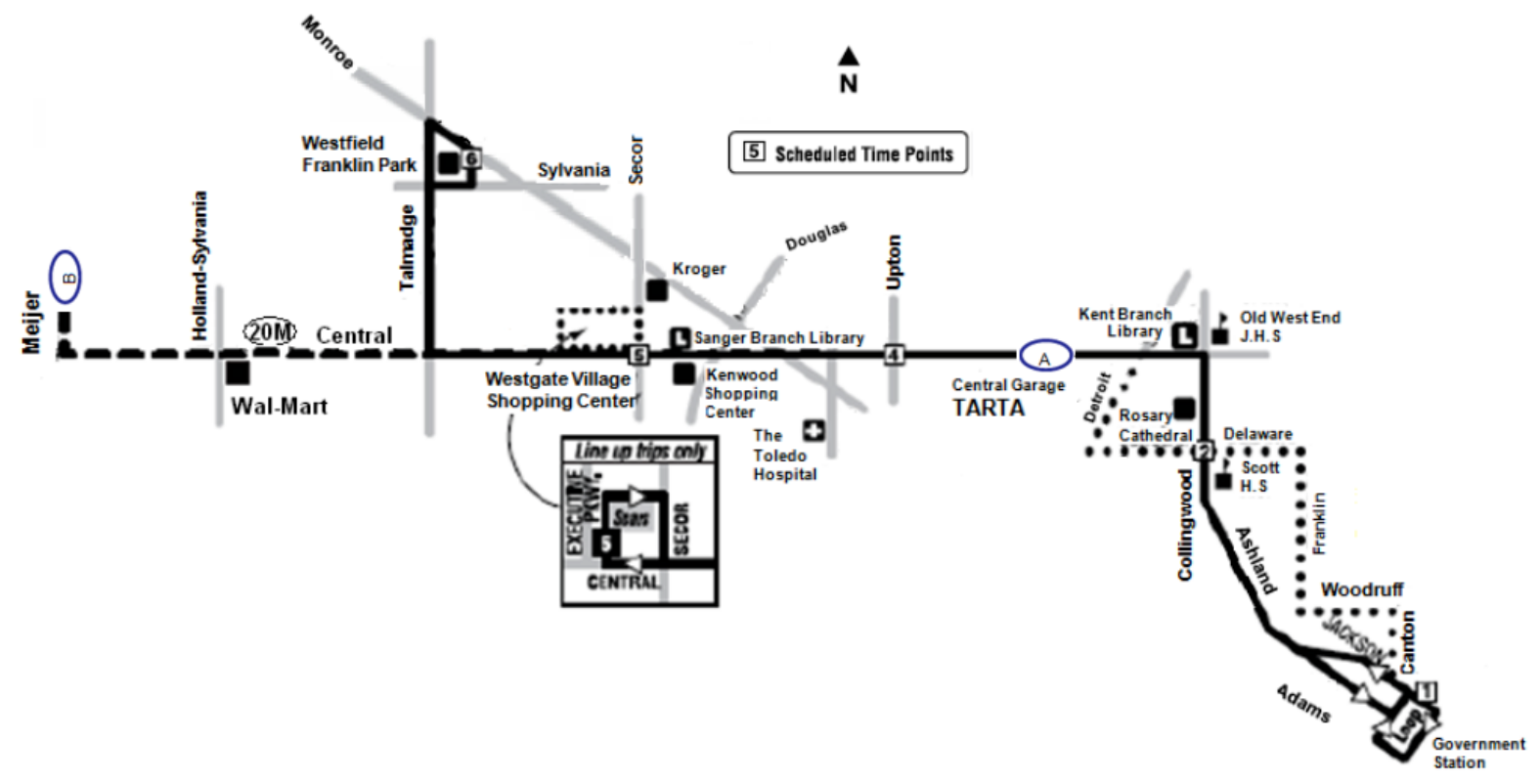

Fig. (1). Map showing test route between TARTA garage (A) and Meijer (B).

Table 1. Instrumentation Summary

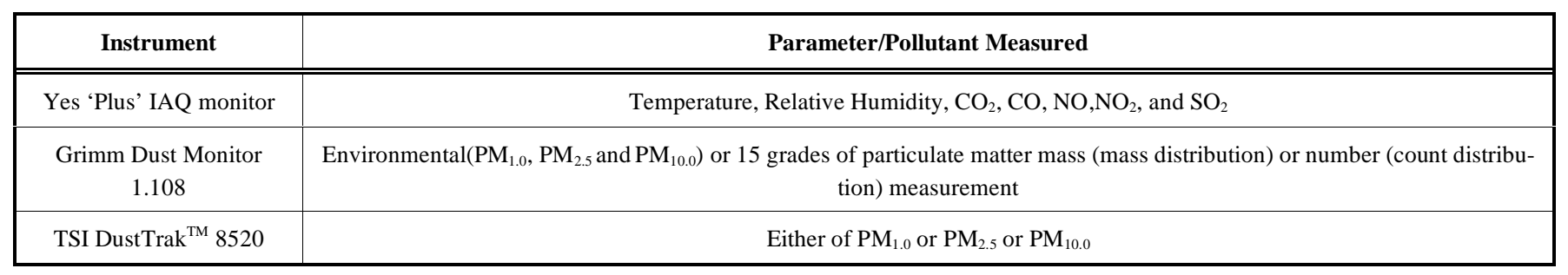

lutant levels to be higher than outdoor pollutant levels, and indoor $\mathrm{CO}_{2}$ levels to be mainly dependent on passengers.

However, none of these studies have discussed the occupant's exposure to pollutants inside vehicles operating on biodiesel fuels. Also, none of these studies have discussed in detail the experimental setup protocol required to continuously monitor the in-vehicle pollutants over a longer period of time. In addition to providing a detailed discussion on the experimental setup protocol required for continuous monitoring of in-vehicle pollutants, this article presents a comparison of the occupant exposures to monitored vehicular pollutants in biodiesel (B20) and ultra low sulfur diesel (ULSD) buses. This study helps in better understanding of the indoor microenvironment of public transport buses running on biodiesel fuels while previous studies have focused on determining the levels of exposures in vehicles operating on conventional diesel fuels. This pilot study uses two buses with one bus running on biodiesel and the other using ultra low sulfur diesel. The research is aimed at filling the knowledge gap and it is hoped that more research be carried out using different blends of biodiesel on more number of buses to better understand in-vehicle microenvironments that use biodiesel fuels.

The real-time in-vehicle pollutant data collected included particulate matter less than 2.5 micrometer $\left(\mathrm{PM}_{2.5}\right)$, carbon dioxide $\left(\mathrm{CO}_{2}\right)$, carbon monoxide $(\mathrm{CO})$, sulfur dioxide $\left(\mathrm{SO}_{2}\right)$, nitric oxide (NO), and nitrogen dioxide $\left(\mathrm{NO}_{2}\right)$. In addition to these pollutants, indoor temperature (Temp.) and indoor rela- tive humidity $(\mathrm{RH})$ were also measured inside the public transport buses. The particulate matter data were collected using Grimm Dust Monitor 1.108 and TSI DustTrak ${ }^{\mathrm{TM}} 8520$ while the gaseous pollutant levels along with temperature and relative humidity were monitored using Yes 'Plus' IAQ monitor. Occupant's exposure to in-vehicle pollutant levels was considered in studying the indoor environment for each bus by considering the respective time of the day during which different drivers operate on each bus.

\section{METHODOLOGY}

\subsection{Experimental Setup}

This research followed a comprehensive indoor air quality monitoring methodology developed by Vijayan [14]. The fleet selected for the study was the 500 series Thomas built buses (acquired by Detroit Diesel) of the TARTA line up, with a Mercedes Benz MBE 900 engine. After selecting the fleet, each bus in the selected fleet was checked if all the cameras inside the bus are working. This enabled the researchers in knowing the buses to which the experimental setup needs to be shifted beforehand in case of a breakdown or any other unexpected problems. The route selected for the test run was Route \# 20 which runs between TARTA garage (A) and Meijer (B) on the Central Avenue strip (refer Fig. 1). The distance between TARTA garage and Meijer on Central Avenue is 7.7 miles and it takes about 14 minutes to commute from one place to another. Two buses were selected from the 500 series in which all the cameras were in working 

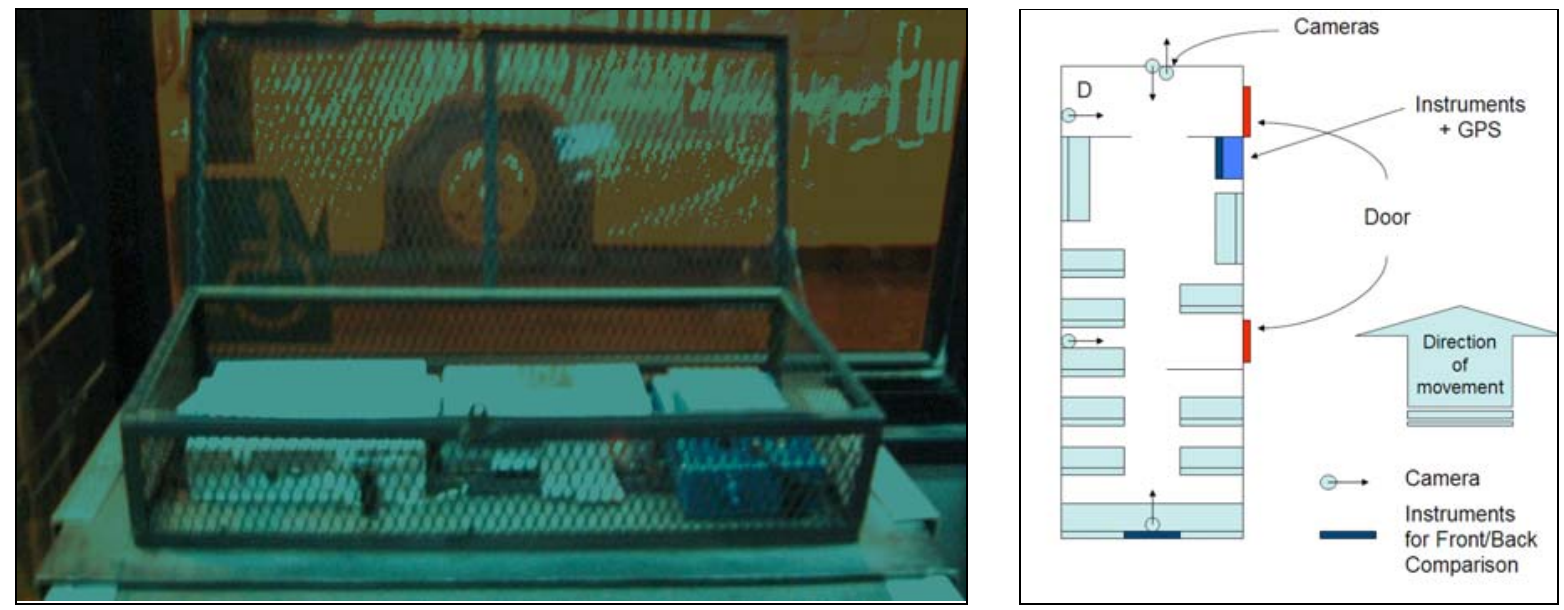

Fig. (2). Experimental setup in the bus.

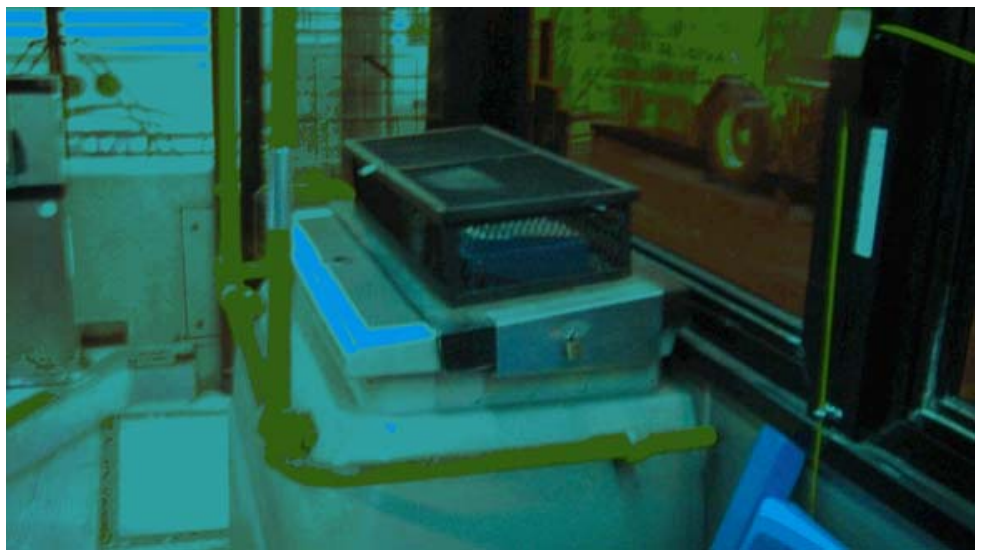

Fig. (3). Locking mechanism provided to hold the cage in a fixed position.

condition with one bus running on biodiesel and the other running on ultra low sulfur diesel to assess the in-vehicle air quality. Both the buses selected for the test run were 'Thermo King' air conditioned and outdoor air penetrates indoors mainly through windows (no: 10) and doors (no: 2) when opened. Biodiesel bus had a mileage of $106 \mathrm{~K}$ while ULSD bus had a mileage of $108 \mathrm{~K}$. Both the selected test run buses operated on the same route with a time lag of 12-20 min between each run. The locations of the buses, when on the run, were identified by the Geographical Position System (GPS) unit located inside them. The instruments used to assess the indoor air quality were Yes 'Plus' IAQ monitor, Grimm Dust Monitor 1.108, and TSI DustTrak ${ }^{\mathrm{TM}}$ 8520. A set of these three instruments is placed in each bus used for the run. A summary of the functionality of the instruments is given in Table $\mathbf{1}$.

To protect the instruments from being detached from their position, a wire mesh cage/box is provided as a shield and Velcro attachments are provided at the bottom to hold the instruments in a fixed position. The wire box is placed at the front end of the bus, near the door over the enclosure built for GPS systems inside the bus. A glass panel separates instrument cage and door (refer Fig. 2). The box is attached to the enclosure using a locking mechanism. The instrument is placed at the sitting level of the passengers and its location is based on the ease of access to power supply and safety of the instrument (refer Fig. 3). The instruments drew power continuously from the AC adapters connected to an inverter inside the bus.

\subsection{Data Collection and Quality}

Indoor air quality was monitored $24 \times 7$ by the three instruments on a 1-second interval and provided the output as 1-minute averages. The collected data were stored in the inbuilt memory cards and the collected data were frequently downloaded to a laptop to ensure proper working of the instruments. To make sure that the data collected were good, Yes 'Plus' monitors were calibrated each week for $\mathrm{CO}_{2}, \mathrm{CO}$, $\mathrm{NO}, \mathrm{NO}_{2}$, and $\mathrm{SO}_{2}$ sensors using calibration gases supplied by CALGAZ. Since, the instruments were calibrated on a weekly basis and not on a daily basis, there could have been some minor errors caused by the instruments. The instruments were cross checked at the end of each week before calibration and it was observed that there was little or no difference in the instrument readings when cross checked. If the difference in the readings of the instruments before calibration was observed to be considerable, all such data were not used for the analysis. The equipment required for calibration consisted of a 0.5 liter per minute (lpm) fixed flow regulator (since the instrument had a low draw rate) and a factory supplied inlet fixture to flow the gases. A summary of the details of calibration of different sensors is given in Table 2 . 
Table 2. Calibration Details

\begin{tabular}{|c|c|c|c|c|}
\hline Sensor & Range & Span Calibration : Gas Concentration & Zero Gas & Span Calibration Gas \\
\hline \hline $\mathrm{CO}_{2}$ & $0-5000 \mathrm{ppm}$ & $2000 \mathrm{ppm}$ & $99.9 \% \mathrm{~N} 2$ & $\mathrm{CO}_{2}$ \\
\hline $\mathrm{CO}$ & $0-50 \mathrm{ppm}$ & $25 \mathrm{ppm}$ & Zero air & $\mathrm{CO}$ \\
\hline $\mathrm{NO}$ & $0-100 \mathrm{ppm}$ & $50 \mathrm{ppm}$ & Zero air & $\mathrm{NO}_{2}$ \\
\hline $\mathrm{NO}_{2}$ & $0-5 \mathrm{ppm}$ & $5 \mathrm{ppm}$ & Zero air & $\mathrm{SO}_{2}$ \\
\hline $\mathrm{SO}_{2}$ & $0-20 \mathrm{ppm}$ & $5 \mathrm{ppm}$ & & $\mathrm{N} 2$ \\
\hline
\end{tabular}

Table 3. Summary of Indoor Air Quality Guidelines

\begin{tabular}{|c|c|c|c|}
\hline Parameter & TWA Guidelines & PEL Guidelines & STEL/C/IDLH Guidelines \\
\hline Temperature & $\begin{array}{l}\text { ASHRAE: } 68 \text { - } 75 \text { (winter) } \\
\text { ASHRAE: } 73 \text { - } 79 \text { (summer) }\end{array}$ & & \\
\hline Humidity & ASHRAE: $30 \%-60 \%$ & & \\
\hline $\begin{array}{l}\text { Particulate Matter } \\
\qquad(\mathrm{PM})\end{array}$ & $\begin{aligned} \mathrm{PM}_{10} & =150 \mu \mathrm{g} / \mathrm{m}^{3} \text { (annual) } \\
\mathrm{PM}_{2.5} & =35 \mu \mathrm{g} / \mathrm{m}^{3} \text { (24 hrs) } \\
& =15 \mu \mathrm{g} / \mathrm{m}^{3} \text { (annual) }\end{aligned}$ & & \\
\hline $\begin{array}{l}\text { Carbon dioxide } \\
\qquad\left(\mathrm{CO}_{2}\right)\end{array}$ & $\begin{array}{l}\text { ACGIH TLV-TWA, NIOSH } 10 \mathrm{hr} \text { TWA }=5,000 \mathrm{ppm} \\
\text { Maximum acceptable indoor level }=2,500 \mathrm{ppm}[16] \\
\text { Maximum comfort concentration }=1,000 \mathrm{ppm}[16] \\
\text { Preferred level }=500-800 \mathrm{ppm}[16]\end{array}$ & OSHA PEL $=5,000 \mathrm{ppm}$ & $\begin{array}{c}\text { ACGIH TLV-STEL/C, NIOSH STEL }= \\
\quad 30,000 \mathrm{ppm}\end{array}$ \\
\hline $\begin{array}{l}\text { Carbon monoxide } \\
\qquad(\mathrm{CO})\end{array}$ & $\begin{array}{c}\text { OSHA }(8 \mathrm{hr}) \text { TWA }=50 \mathrm{ppm} \\
\text { ACGIH TLV-TWA }(8 \mathrm{hr})=25 \mathrm{ppm} \\
\text { NIOSH REL TLV-TWA }(8 \mathrm{hr})=35 \mathrm{ppm}\end{array}$ & OSHA PEL $=50 \mathrm{ppm}$ & $\begin{array}{l}\text { NIOSH IDLH }=1200 \mathrm{ppm} \\
\text { STEL } / \mathrm{C}=400 \mathrm{ppm} \\
\text { NIOSH C }=200 \mathrm{ppm}\end{array}$ \\
\hline $\begin{array}{l}\text { Nitrogen dioxide } \\
\qquad\left(\mathrm{NO}_{2}\right)\end{array}$ & ACGIH TLV-TWA $=3$ ppm & & $\begin{array}{c}\text { OSHA STEL } / \mathrm{C}=5 \mathrm{ppm} \\
\text { OSHA IDLH: } 50 \mathrm{ppm} / 30 \mathrm{~min}\end{array}$ \\
\hline Nitric oxide (NO) & ACGIH TWA, NIOSH REL TWA $=25$ ppm & OSHA PEL $=25 \mathrm{ppm}$ & OSHA IDLH $=100 \mathrm{ppm} / 30 \mathrm{~min}$ \\
\hline Sulfur dioxide $\left(\mathrm{SO}_{2}\right)$ & ACGIH TLV-TWA, OSHA PEL-TWA = 2 ppm & & $\begin{array}{c}\text { ACGIH TLV-STEL/C, OSHA PEL- } \\
\text { STEL }=5 \mathrm{ppm}\end{array}$ \\
\hline
\end{tabular}

The Grimm Dust Monitor 1.108 and TSI DustTrak ${ }^{\mathrm{TM}}$ 8520 were regularly cleaned with canned air and the particulate filters were frequently replaced. It was made sure that the Grimm Dust Monitors were still under factory calibration and this ensured quality data from it. The TSI DustTrak monitors were zero checked regularly and the nozzles cleaned to obtain good quality data. The data downloaded from all the instruments have been set for 1 minute interval that is averaged to 1-hour for analysis. To make sure that the differences in pollutant levels are representative of the respective vehicular indoor microenvironments and not a result of error caused by difference in measuring pollutant levels by the instruments, data were collected for a couple of hours at the end of each week just before and immediately after maintenance to cross check for any differences in the data collected. Images recorded by cameras inside the bus were stored to a hard drive that were analyzed to determine real time variables like passenger count, vehicles surrounding, and ventilation settings.

Vijayan and Kumar [15] observed in-vehicle pollutant levels to vary with route selected for the study. Sometimes the bus did not go on the designated route and hence, all such data were removed from the analysis presented in this paper to have a common representative sample for comparing driver's exposure along a fixed route over a longer period of time. Particulate matter $\left(\mathrm{PM}_{2.5}\right)$ data collected using Grimm Dust Monitor 1.108 between Sep. 2007 and Mar. 2008; and gaseous pollutant data collected using Yes Plus monitor between Apr. 2007 and Feb. 2008 were used to study the driver's exposure to in-vehicle pollutants in both B20 and ULSD buses. Gaseous pollutant data were not collected during the month of July. 2007 in ULSD bus as the instruments were sent for factory calibration and hence driver's exposures in that month were not obtained.

\section{REVIEW OF INDOOR AIR QUALITY GUIDE- LINES}

A summary of the indoor air pollutants guidelines as of 2010 in practice are given in Table 3. The Time Weighted Average (TWA) in Table $\mathbf{3}$ is defined as the average exposure to a pollutant to which a person may be exposed without adverse effect over a period such as 8 -hr/day or 40 -hr/week. 
Permissible Exposure Limit (PEL) is the maximum concentration of a pollutant to which a worker may be exposed to under OSHA regulations. TLV-STEL is the immediate exposure for duration shorter than 15 minutes that cannot be repeated more than 4 times per day. TLV-C is the absolute exposure limit that should not be exceeded at any time. OSHA sets regulatory exposure limits/levels such as the PEL and TWA. Ceiling (C) value is the exposure limit which should not be exceeded at any time. Immediately Dangerous to Life and Health (IDLH) value is the maximum limit to which a healthy individual can be exposed for 30 minutes and escape without suffering irreversible health effects or impairing symptoms.

\section{DRIVER'S EXPOSURE}

This section provides a discussion on the temporal changes and driver's/commuter's exposure to monitored invehicle pollutants with an emphasis on statistical significance of the exposure results. Temporal changes are a result of variation in pollutant concentrations observed on an hourly basis and occupant's exposure is summarized based on the drivers working hours in a day. The authors obtained the driver schedule from TARTA transportation department and the 8-hr TWA values for each bus were calculated using equation 4.1. Both the buses were run by 3 different drivers who operated during different hours of a day. Drivers changed every day at 9:28 AM and 3:28 PM (Driver 1: 5:10 AM - 9:28 AM; Driver 2: 9:28 AM - 3:28 PM; Driver 3: 3:28 PM - 11:40 PM). From here on the terms Morning, Afternoon, and Evening/Night in the exposure results refers to the respective time periods during which driver 1 , driver 2 , and driver 3 operates and represents the three drivers exposure in the bus considered.

$$
T W A=\frac{\sum c_{i} t_{i}}{8}
$$

The two sample t test was used to evaluate if the difference in mean 8-hr TWA values computed from drivers working hours for different time periods of a day in B20 and ULSD fuelled buses is statistically significant or occurred by chance. One way analysis of variance (ANOVA) was used to determine if there are any statistically significant differences in mean exposure levels during the three different time periods of a day for a single bus considered. Table 4 summarizes the average, minimum, and maximum 8-hr TWA concentrations of $\mathrm{CO}_{2}, \mathrm{CO}, \mathrm{NO}, \mathrm{NO}_{2}, \mathrm{SO}_{2}$, and $\mathrm{PM}_{2.5}$ as observed in B20 and ULSD buses.

2 sample t test: The null hypothesis $\left(\mathrm{H}_{0}\right)$ is the means of 8-hr TWA pollutant concentration in both B20 and ULSD buses are same. The alternative hypothesis $\left(\mathrm{H}_{\mathrm{a}}\right)$ is the means of 8-hr TWA pollutant concentration in both B20 and ULSD buses are different. We reject the null hypothesis and accept the alternate hypothesis that difference between B20 and ULSD 8-hr TWA means is not zero and the difference is statistically significant if $p$-value $<0.05(\alpha)$. We accept the null hypothesis and reject the alternate hypothesis that difference between B20 and ULSD 8-hr TWA is zero and the difference in TWA means is not statistically significant if $\mathrm{p}$ value $>0.05(\alpha)$. MINITAB $15^{\circledR}$ was used to perform this test.

Analysis of Variance (ANOVA): ANOVA helps one identify whether there is sufficient evidence to say that exposure levels of occupants in the same bus are significantly different. The null hypothesis $\left(\mathrm{H}_{0}\right)$ is that mean 8 -hr TWA exposure levels are equal for occupants during morning, afternoon, and evening/night in respective buses. The alternative hypothesis $\left(\mathrm{H}_{\mathrm{a}}\right)$ is that mean 8-hr TWA exposure levels are not equal and there are significant differences for the exposure levels to occupants during morning, afternoon, and evening/night in respective buses. One can reject the null hypothesis $\left(\mathrm{H}_{0}\right)$ and accept the alternate hypothesis $\left(\mathrm{H}_{\mathrm{a}}\right)$ that there is statistically significant difference between occupant exposure levels during three time periods for any single bus if p-value $<0.05(\alpha)$. One needs to accept the null hypothesis $\left(\mathrm{H}_{0}\right)$ that there is statistically no significant difference between occupant exposures during three time periods for any single bus considered and reject the alternate hypothesis $\left(\mathrm{H}_{\mathrm{a}}\right)$ if $\mathrm{p}$-value $>0.05(\alpha)$. Tukey post hoc test was used to determine if there are any statistically significant differences between the occupant exposure levels in either B20 or ULSD bus. SPSS $17^{\circledR}$ was used to perform this test.

\section{1. $\mathrm{CO}_{2}$ Concentration}

Figs. (4) and (5) show the occupant's exposure to carbon dioxide during morning, afternoon, and evening/night in B20 and ULSD buses respectively. The carbon dioxide levels were observed to be relatively lower in a B20 bus as compared to ULSD bus as can be seen from Fig. (4) and Fig. (5). Occupants coming in during the morning run of biodiesel

Table 4. 8-hr TWA Pollutant Concentration Statistics

\begin{tabular}{|c|c|c|c|c|c|c|}
\hline & \multicolumn{3}{|c|}{ B20 } & \multicolumn{3}{c|}{ ULSD } \\
\cline { 2 - 6 } & $\mathbf{X} \pm$ SD & Min & Max & X SD & Max \\
\hline \hline $\mathbf{C O}_{2}(\mathbf{p p m})$ & $559.67( \pm 45.01)$ & 454.72 & 648.91 & $632.20( \pm 102.70)$ & 500.10 & 882.90 \\
\hline $\mathbf{C O}(\mathbf{p p m})$ & $18.33( \pm 9.23)$ & 8.04 & 44.81 & $8.08( \pm 1.41)$ & 0.75 & 29.33 \\
\hline $\mathbf{N O}(\mathbf{p p m})$ & $5.23( \pm 4.49)$ & 0.31 & 17.25 & $0.73( \pm 0.21)$ & 0.24 & 5.01 \\
\hline $\mathbf{N O}_{\mathbf{2}}(\mathbf{p p m})$ & $0.13( \pm 0.05)$ & 0.04 & 0.19 & $0.09( \pm 0.06)$ & 0.02 & 0.20 \\
\hline $\mathbf{S O}_{\mathbf{2}}(\mathbf{p p m})$ & $0.13( \pm 0.01)$ & 0.00 & 0.21 & $0.39( \pm 0.04)$ & 0.00 & 0.74 \\
\hline $\mathbf{P M}_{2.5}\left(\boldsymbol{\mu g} / \mathbf{m}^{\mathbf{3}}\right)$ & $13.75( \pm 4.24)$ & 7.05 & 24.24 & $13.33( \pm 5.49)$ & 7.94 & 25.48 \\
\hline
\end{tabular}




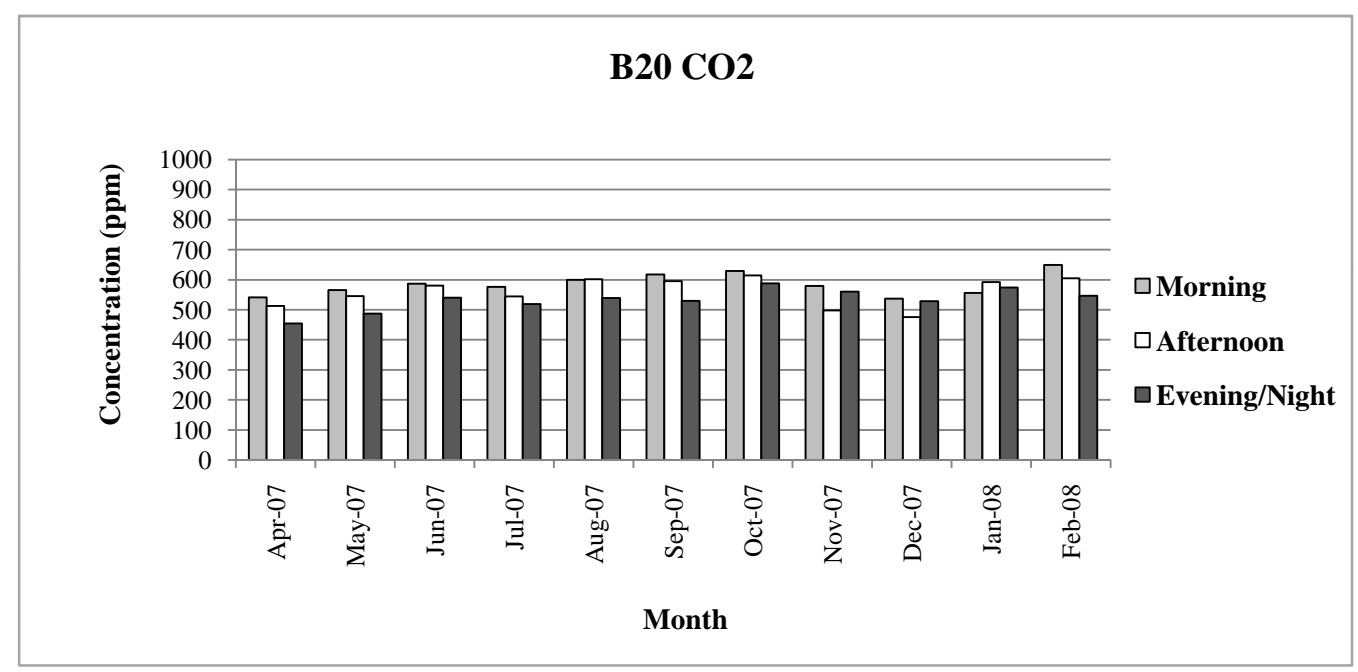

Fig. (4). TWA for $\mathrm{CO}_{2}$ in $\mathrm{B} 20$ bus.

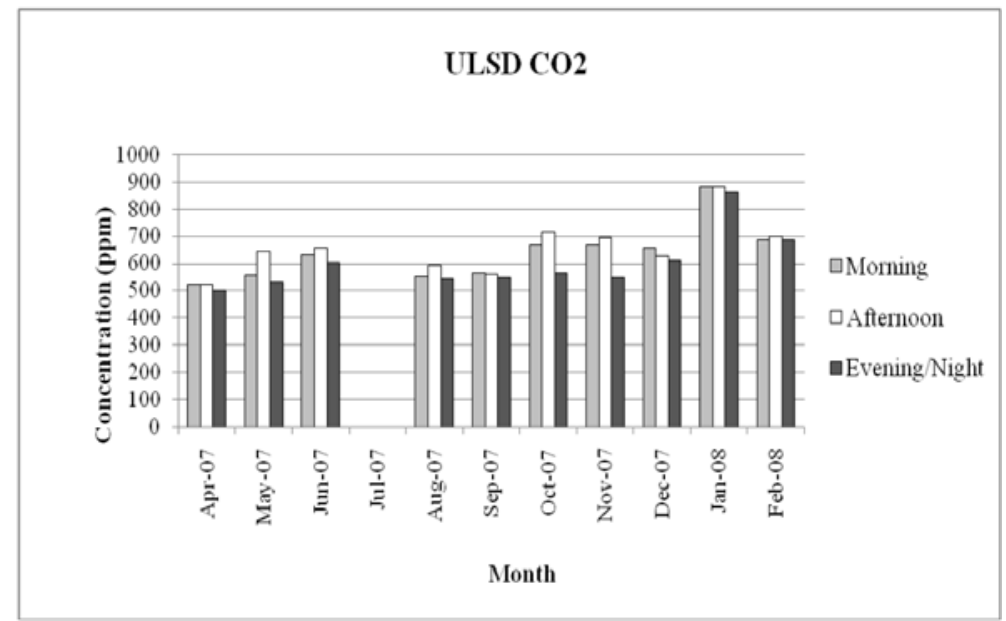

Fig. (5). TWA for $\mathrm{CO}_{2}$ in ULSD bus.

bus and occupants coming in during the afternoon run of ultra low sulfur diesel bus are the most exposed to carbon dioxide in respective buses. The carbon dioxide levels did not exceed the indoor TWA standard of $5000 \mathrm{ppm}$ and are within maximum comfort concentration of $1000 \mathrm{ppm}$ in both the buses. On performing ANOVA, it was observed that there is statistically significant difference for occupant's exposure to $\mathrm{CO}_{2}$ in $\mathrm{B} 20$ bus $(\mathrm{P}=0.020)$ while there is no statistically significant difference for occupant's exposure in ULSD bus $(P=0.422)$. Table 5 presents a summary of the statistical significance of the difference in occupant exposure levels to carbon dioxide during morning, afternoon, and evening/night time periods in both B20 and ULSD buses obtained using Tukey post hoc analysis. From Table $\mathbf{5}$ it can be observed that there is statistically no significant difference in exposure to $\mathrm{CO}_{2}$ between any two set of occupant time periods in a ULSD bus (all p-values > 0.05) while there is statistically significant difference only between morning and evening/night time periods of biodiesel bus $(\mathrm{P}=0.015)$. Occupant exposure during morning in a B20 bus $(\mu=585.28$ ppm) is statistically significantly higher than occupant exposure during evening/night run in a B20 bus $(\mu=533.38$ ppm).
Two sample $t$ test indicated that there is statistically significant difference between the mean 8-hr TWA exposure to carbon dioxide in B20 and ULSD buses during morning, afternoon, and evening/night $(\mathrm{T}=-3.57, \mathrm{P}=0.001)$. Occupant exposure to carbon dioxide in a ULSD bus $(\mu=632.20$ ppm) is significantly higher as compared to the occupant exposure in a B20 bus $(\mu=559.67 \mathrm{ppm})$. The carbon dioxide pollutant buildup within the bus compartment is mainly due to the passengers and occupants experienced higher exposures during peak hours.

Fig. (6) shows the variation of carbon dioxide with passengers and vehicles with respect to weekday and weekend in the month of June in a biodiesel bus. From Fig. (6), one can observe the passenger ridership to be higher during morning and evening peak hours in a weekday as compared to the respective weekend peak hours and it is quite opposite for majority of the time during non-peak hours. Vehicular traffic was observed to be higher in the evening as compared to morning during weekdays and it is the opposite during weekends. It can also be observed from Fig. (6) that invehicle carbon dioxide concentrations were mainly dependent on passenger ridership for majority of the day while vehicles moving ahead of the vehicle were also found to be 
Table 5. ANOVA Results for Difference in $\mathrm{CO}_{2}$ Exposure Levels in $\mathrm{B20}$ and ULSD Buses

\begin{tabular}{|c|c|c|c|c|c|}
\hline \multicolumn{2}{|c|}{ B20 Drivers } & P - Value & ULSD Drivers & P - Value \\
\hline \hline \multirow{2}{*}{ Morning $(\mu=585.28)$} & Afternoon $(\mu=560.36)$ & .338 & \multirow{2}{*}{ Morning $(\mu=638.75)$} & Afternoon $(\mu=659.12)$ & .898 \\
\cline { 2 - 4 } & Evening/Night $(\mu=533.38)$ & .015 & & Evening/Night $(\mu=598.63)$ & .663 \\
\hline \multirow{2}{*}{ Afternoon $(\mu=560.36)$} & Evening/Night $(\mu=533.38)$ & .283 & Afternoon $(\mu=659.12)$ & Evening/Night $(\mu=598.63)$ & .401 \\
\hline
\end{tabular}

\section{CO2 Variation with Passengers and Vehicular Traffic}

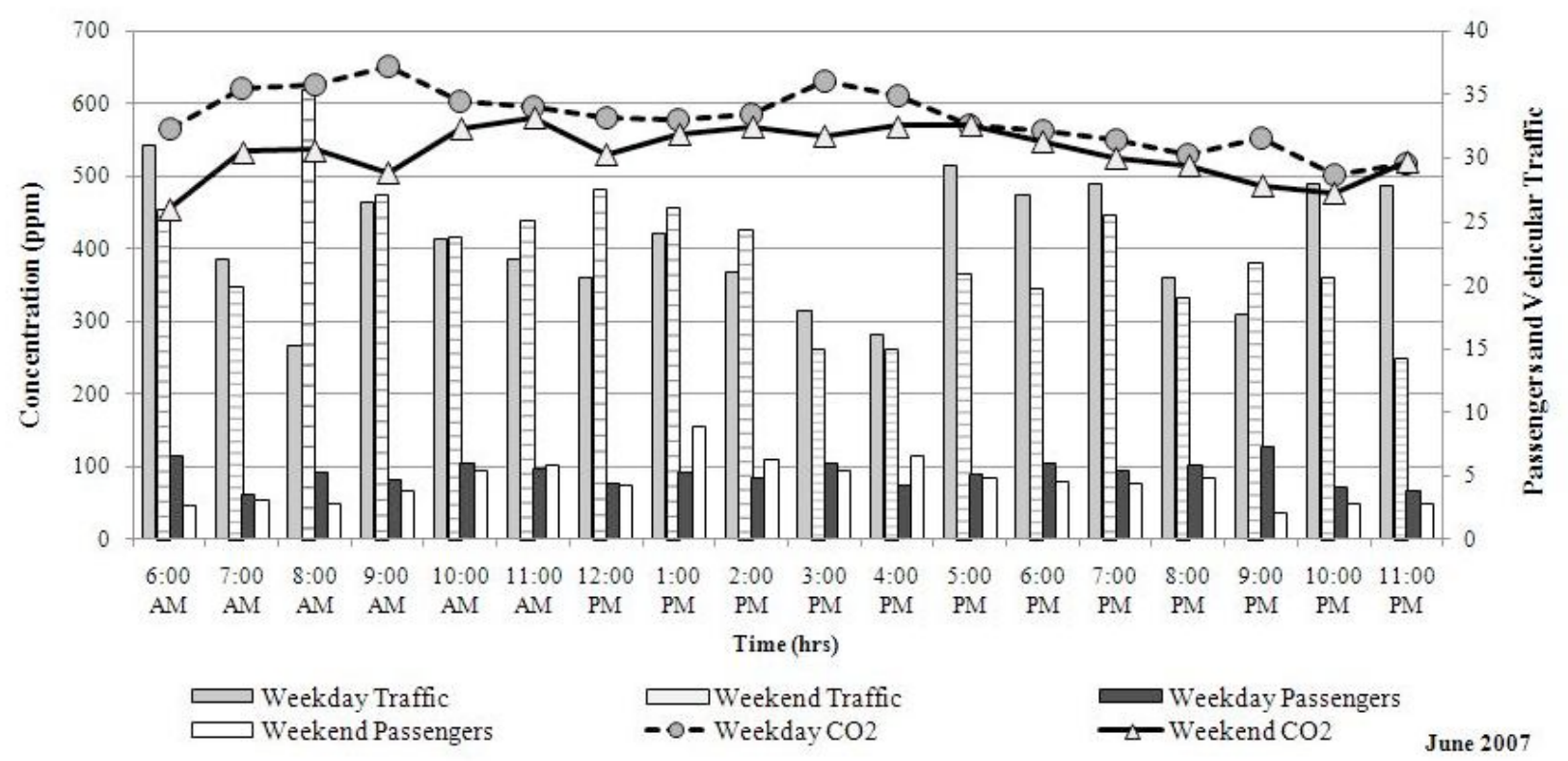

Fig. (6). $\mathrm{CO}_{2}$ concentration trend in a $\mathrm{B} 20$ bus.

playing a major role in influencing vehicular carbon dioxide levels. Relatively higher $\mathrm{CO}_{2}$ concentrations were observed during weekdays as compared to a weekend mainly due to higher number of passengers commuting between their workplace and homes. Similar trends were observed for $\mathrm{CO}_{2}$ in both the test buses. Vijayan and Kumar [15] and Kadiyala and Kumar [17] have performed regression and regression tree analysis respectively and observed passenger ridership and vehicles moving ahead of the test bus as important factors influencing vehicular carbon dioxide levels in both B20 and ULSD buses.

\subsection{CO Concentration}

Figs. (7) and (8) show the levels of exposure of occupants to carbon monoxide during morning, afternoon, and evening/night in biodiesel and ultra low sulfur diesel buses respectively. It can be observed from Figs. (7) and (8) that CO levels were found to be relatively higher in a B20 bus as compared to ULSD bus. Occupants coming in during the morning run of B20 bus and occupants coming in during the afternoon run of ULSD bus are more exposed to carbon monoxide as compared to occupants coming in during other time periods in respective buses. The exposure levels were found to be in a range of $5 \mathrm{ppm}$ and $25 \mathrm{ppm}$ for majority of the months irrespective of the buses. Sometimes the vehicu- lar CO levels exceeded the standard TWA value of $25 \mathrm{ppm}$ as can be observed from Figs. (7) and (8). Higher CO levels inside both the buses could be a result of penetration of $\mathrm{CO}$ exhaust emissions from higher number of lead vehicles with windows opened. This observation was made from the video analysis. On performing ANOVA, it was observed that there is statistically no significant difference for exposure to $\mathrm{CO}$ among B20 occupants $(\mathrm{P}=0.995)$ and ULSD occupants $(\mathrm{P}=$ $0.995)$. Table 6 presents a summary of the statistical significance of the difference in occupant exposure levels to carbon monoxide during morning, afternoon, and evening/night in both B20 and ULSD buses obtained using Tukey post hoc analysis. From Table 6, it can be observed that there is statistically no significant difference in occupant exposure to $\mathrm{CO}$ between any set of time periods of a day on same bus (all pvalues > 0.05).

On performing the two sample $t$ test, it was observed that there is statistically significant difference between the mean 8-hr TWA exposure to carbon monoxide in B20 and ULSD buses ( $\mathrm{T}=4.79, \mathrm{P}=0.000)$. Exposure of occupants to carbon monoxide in a B20 bus $(\mu=18.33 \mathrm{ppm})$ is significantly higher as compared to the occupants exposure in a ULSD bus $(\mu=8.08 \mathrm{ppm})$. 


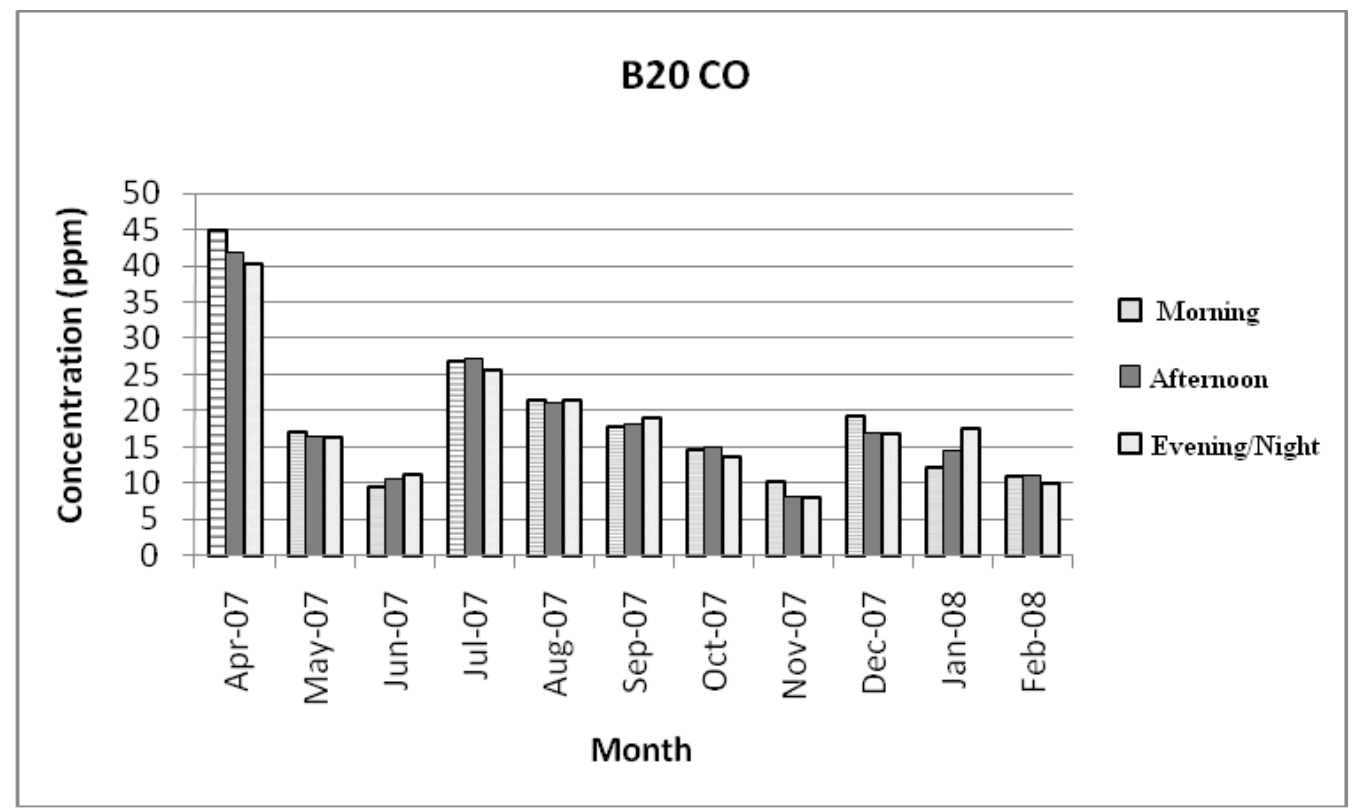

Fig. (7). TWA for $\mathrm{CO}$ in $\mathrm{B} 20$ bus.

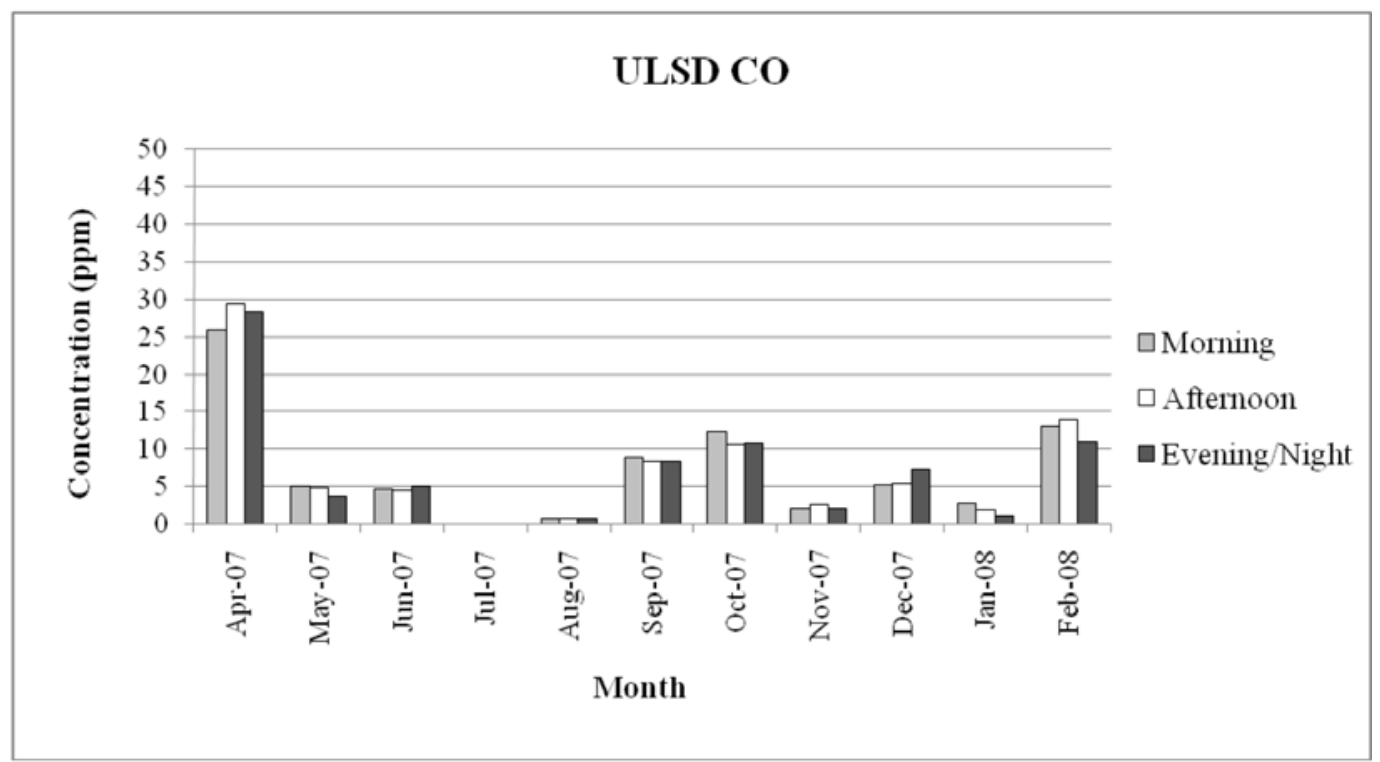

Fig. (8). TWA for CO in ULSD bus.

Fig. (9) shows the variation of carbon monoxide with vehicles during weekdays and weekends in the month of June in a B20 bus. From Fig. (9), one can observe the CO concentrations to be mainly influenced by the vehicular traffic ahead for majority of the time. It can also be seen from Fig. (9) that relatively higher $\mathrm{CO}$ levels were observed during weekends as compared to weekdays. This could be mainly due to higher penetration of $\mathrm{CO}$ from lead vehicle exhaust when more number of windows were observed to be left open during weekends compared to weekdays from the video analysis. It was also observed from the video analysis that heavy vehicles (buses/trucks) constituted majority of the weekend traffic while cars were predominant during weekdays. CO levels varied with vehicular traffic and ventilation settings in both the test buses throughout the test period. Kadiyala and Kumar [17] performed regression tree analysis and observed vehicular CO levels to be mainly influenced by ventilation settings, vehicular traffic, and speed of the vehicle. Similar observations were made by Vijayan and Kumar [15] on performing regression analysis.

\subsection{NO Concentration}

Figs. (10) and (11) represent the occupant's exposure to NO during morning, afternoon, and evening/night in B20 and ULSD buses respectively. Since, data values less than sensor resolution of $0.2 \mathrm{ppm}$ for NO have not been considered for the analysis, TWA values remained to be almost 'zero' throughout the testing period in ULSD bus but varied considerably in some months in a B20 bus as can be seen from Figs. (10) and (11). It can be observed from Figs. (10) and (11) that NO levels were found to be relatively higher in a B20 bus as compared to ULSD bus. Occupants coming in 
Table 6. ANOVA Results for Difference in CO Exposure Levels in B20 and ULSD Buses

\begin{tabular}{|l|c|c|c|c|c|}
\hline \multicolumn{2}{|c|}{ B20 Drivers } & P - Value & \multicolumn{2}{|c|}{ ULSD Drivers } & P - Value \\
Morning $(\mu=18.56)$ & Afternoon $(\mu=18.27)$ & .997 & Afternoon $(\mu=8.24)$ & .999 \\
& Evening/Night $(\mu=18.16)$ & .995 & Morning $(\mu=8.08)$ & Evening/Night $(\mu=7.90)$ & .999 \\
\hline Afternoon $(\mu=18.27)$ & Evening/Night $(\mu=18.16)$ & 1.000 & Afternoon $(\mu=8.24)$ & Evening/Night $(\mu=7.90)$ & .995 \\
\hline
\end{tabular}

\section{CO Variation with Vehicular Traffic}

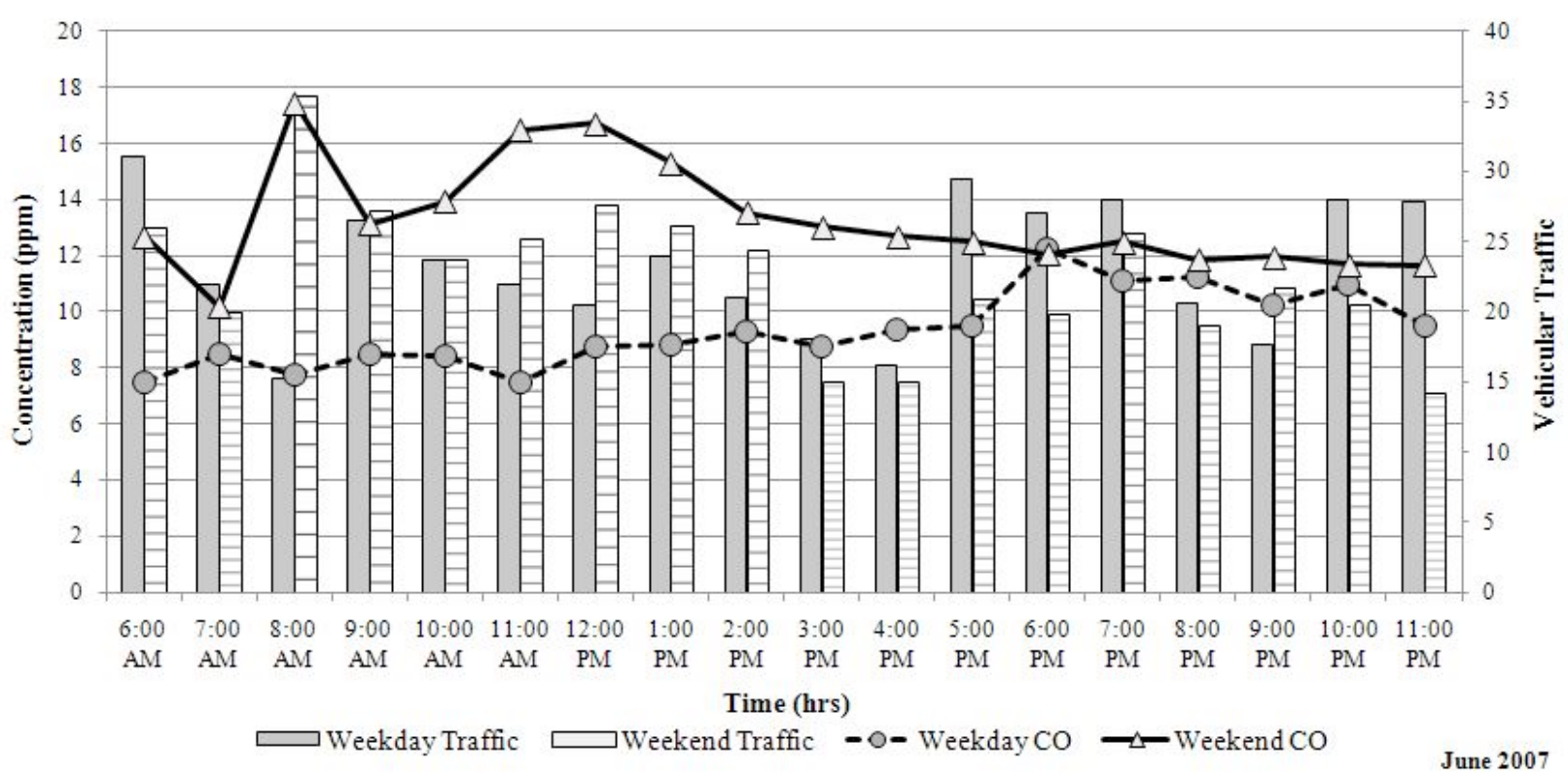

Fig. (9). $\mathrm{CO}$ concentration trend in a B20 bus.

for the morning run in an ultra low sulfur diesel bus and those coming during evening/night in a B20 fuelled bus are the most affected by exposure to NO. The nitric oxide levels in both B20 and ULSD buses are well below the standard TWA value of $25 \mathrm{ppm}$. ANOVA test revealed that there is statistically no significant difference between exposure levels to NO in both $\mathrm{B} 20$ occupants $(\mathrm{P}=0.835)$ and ULSD occupants $(\mathrm{P}=0.567)$. Table 7 presents a summary of the statistical significance of the difference in exposure levels of NO for occupants in morning, afternoon, and evening/night time periods in both B20 and ULSD with Tukey post hoc analysis. From Table 7 it can be observed that there is statistically no significant difference in exposure to nitric oxide between occupants coming in during morning, afternoon, and evening/night in same bus (all p-values >0.05).

Two sample t test for NO concentrations in B20 and ULSD buses revealed that there is statistically significant difference between the mean 8-hr TWA exposures ( $\mathrm{T}=3.34$, $\mathrm{P}=0.004)$. Occupant exposure to nitric oxide in a B20 bus ( $\mu=5.23 \mathrm{ppm})$ is significantly higher as compared to the drivers exposure in a ULSD bus $(\mu=0.73 \mathrm{ppm})$.

Fig. (12) shows the variation of NO with vehicles during weekdays and weekends in the month of June in a B20 bus. From Fig. (12), one can observe the vehicular traffic to be having a major influence on the NO concentrations for majority of the time. Also, one can observe the weekend NO concentrations to be higher as compared to weekday NO concentrations inside the bus. This could be mainly due to higher penetration of NO from lead vehicle exhaust (mainly trucks) when more number of windows that were left open was observed to be higher during weekend as compared to weekday from the video analysis. Vehicular traffic and ventilation settings were observed to be having a major influence on the vehicular NO levels in both the test buses throughout the test period. Vijayan and Kumar [15] and Kadiyala and Kumar [17] observed vehicular traffic and ventilation settings to play a major role in influencing indoor NO levels in both the buses.

\section{4. $\mathrm{NO}_{2}$ Concentration}

The 8-hr TWA nitrogen dioxide levels were found to be 'zero' for most of the months in both B20 and ULSD buses as can be seen in Figs. (13) and (14) respectively. Since, data values less than sensor resolution of $0.01 \mathrm{ppm}$ for $\mathrm{NO}_{2}$ only have been considered for the analysis, TWA values for most of the months remained to be nearly 'zero'. Relatively higher levels of $\mathrm{NO}_{2}$ are observed in a B20 bus as compared to ULSD bus as observed from Figs. (13) and (14). Occupants coming in during morning are the most affected by $\mathrm{NO}_{2}$ in 


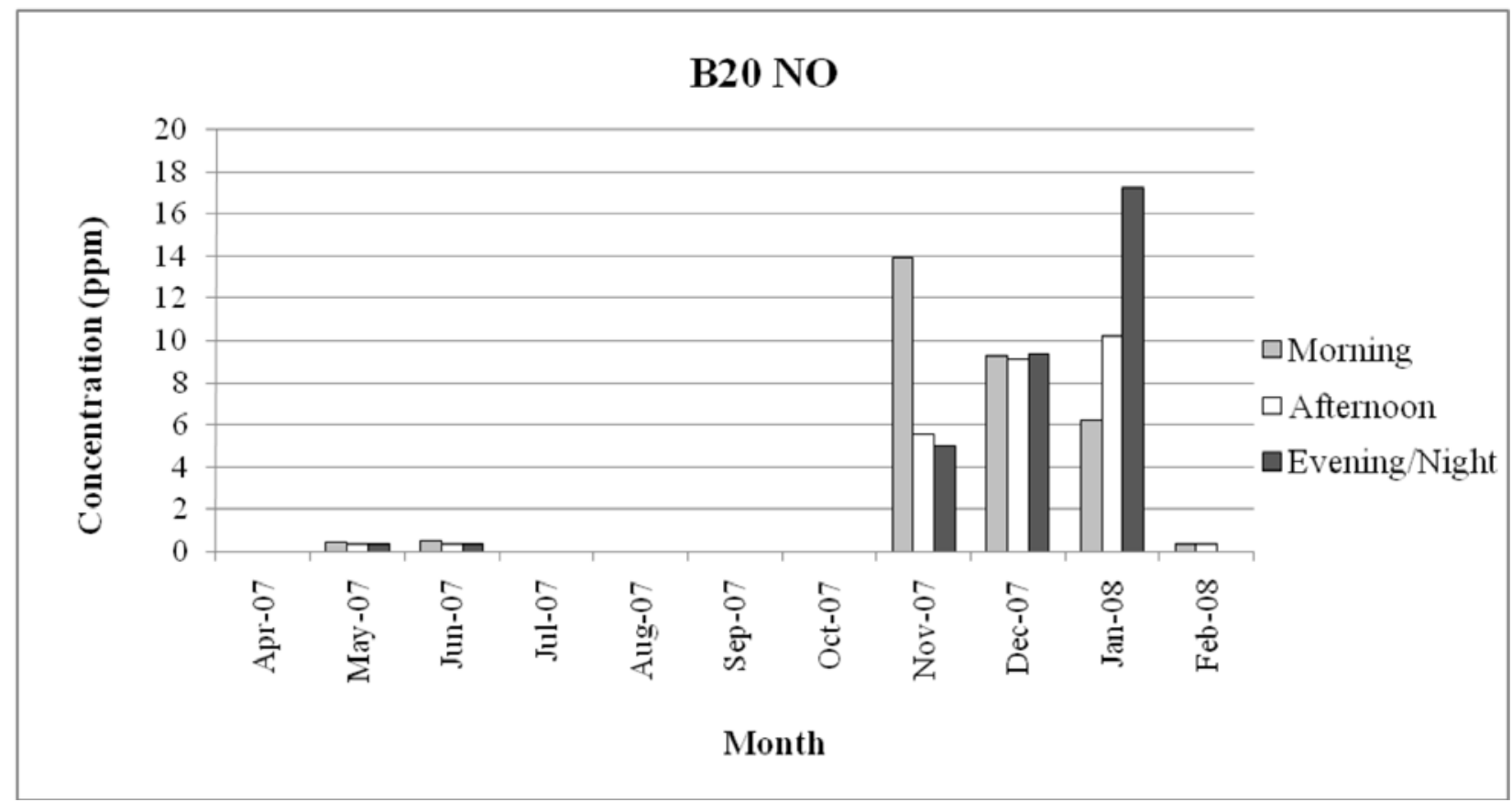

Fig. (10). TWA for NO in B20 bus.

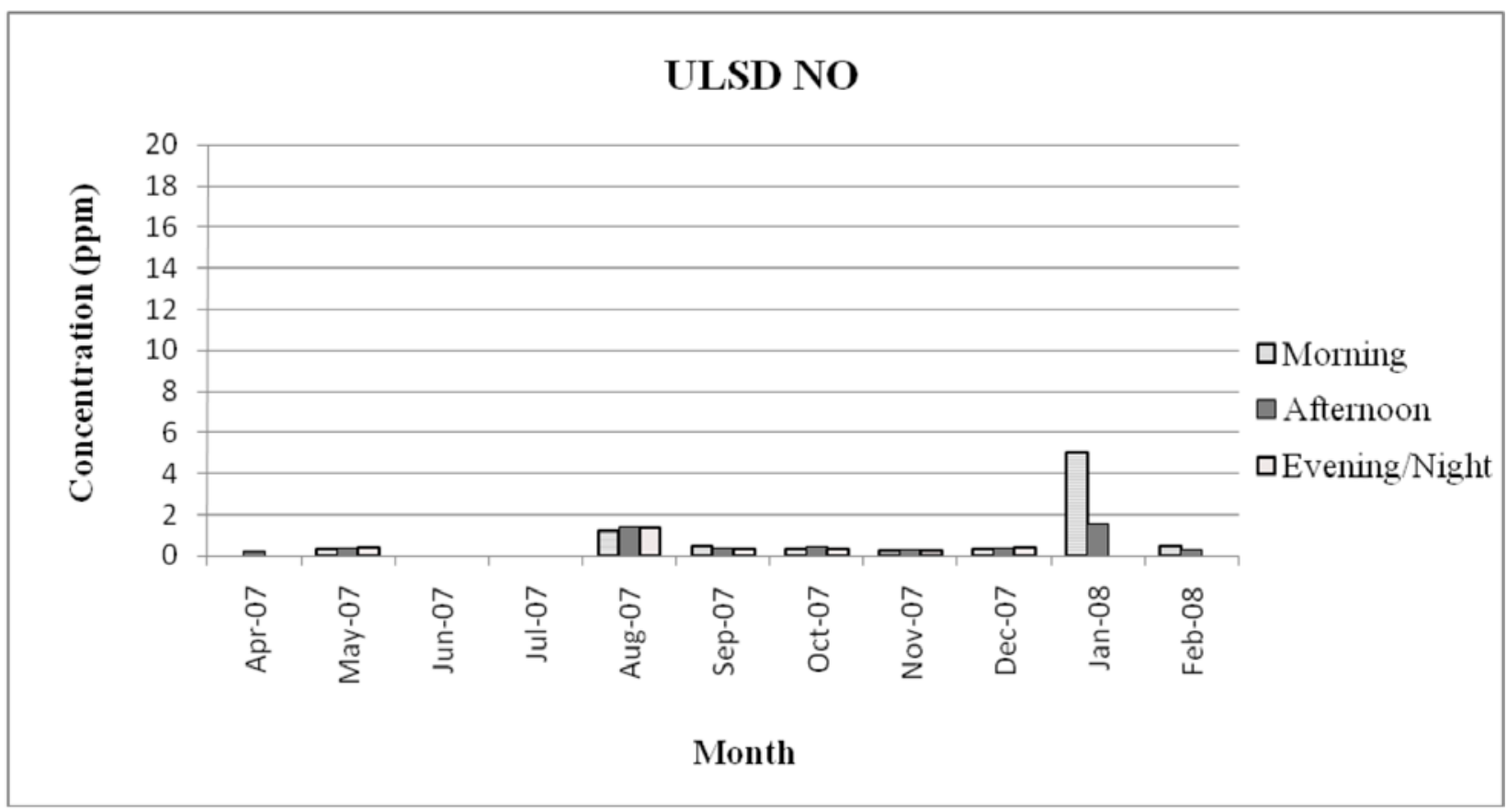

Fig. (11). TWA for NO in ULSD bus.

Table 7. ANOVA Results for Difference in NO Exposure Levels in B20 and ULSD Buses

\begin{tabular}{|c|c|c|c|c|}
\hline \multicolumn{2}{|c|}{ B20 Drivers } & P - Value & ULSD Drivers & P - Value \\
\hline \hline \multirow{2}{*}{ Morning $(\mu=5.11)$} & Afternoon $(\mu=4.33)$ & .971 & \multirow{2}{*}{ Morning $(\mu=1.05)$} & Afternoon $(\mu=0.59)$ \\
\cline { 2 - 3 } & Evening/Night $(\mu=6.44)$ & .924 & & Evening/Night $(\mu=0.51)$ \\
\hline Afternoon $(\mu=4.33)$ & Evening/Night $(\mu=6.44)$ & .822 & Afternoon $(\mu=0.59)$ & Evening/Night $(\mu=0.51)$ \\
\hline
\end{tabular}


NO Variation with Vehicular Traffic

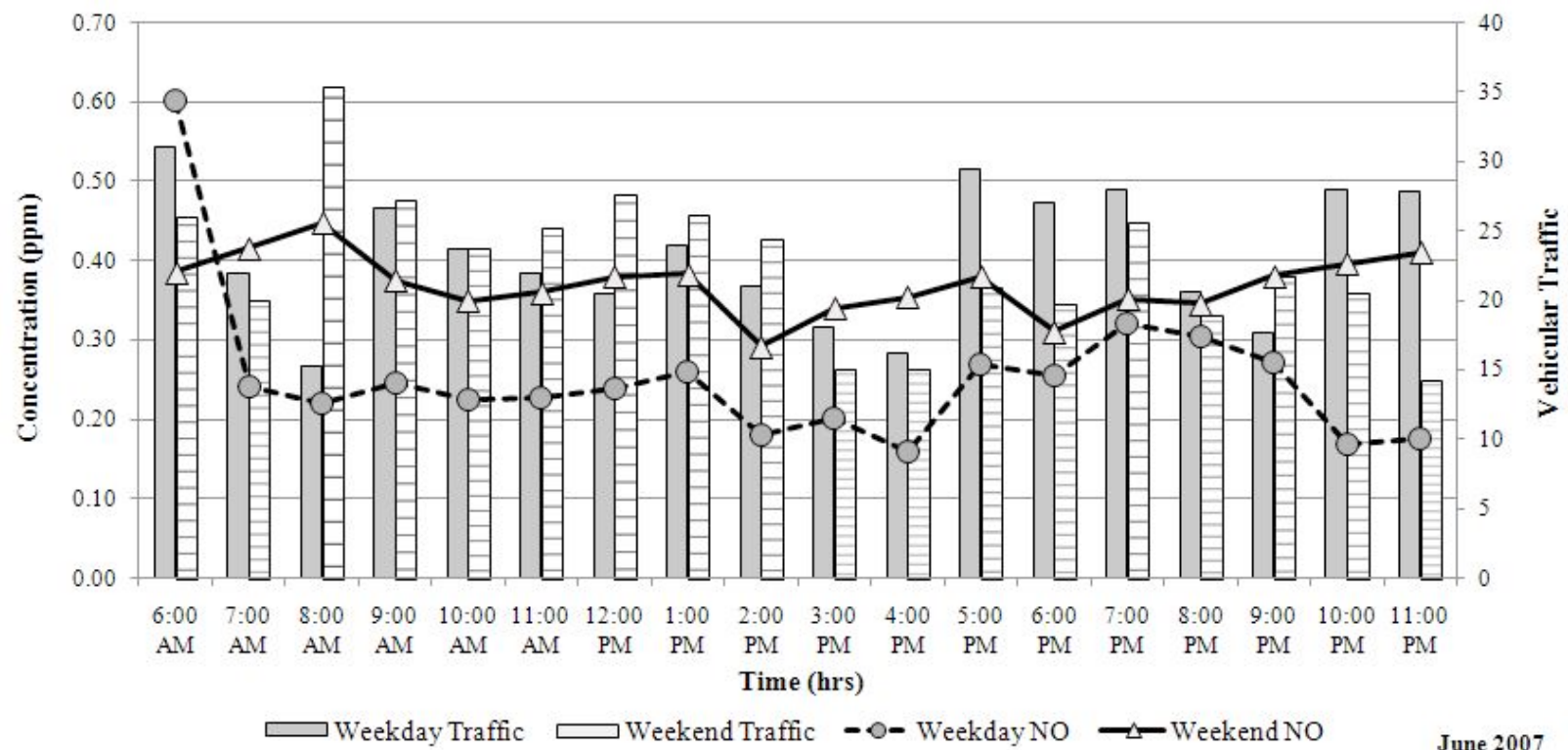

Fig. (12). NO concentration trend in a B20 bus.

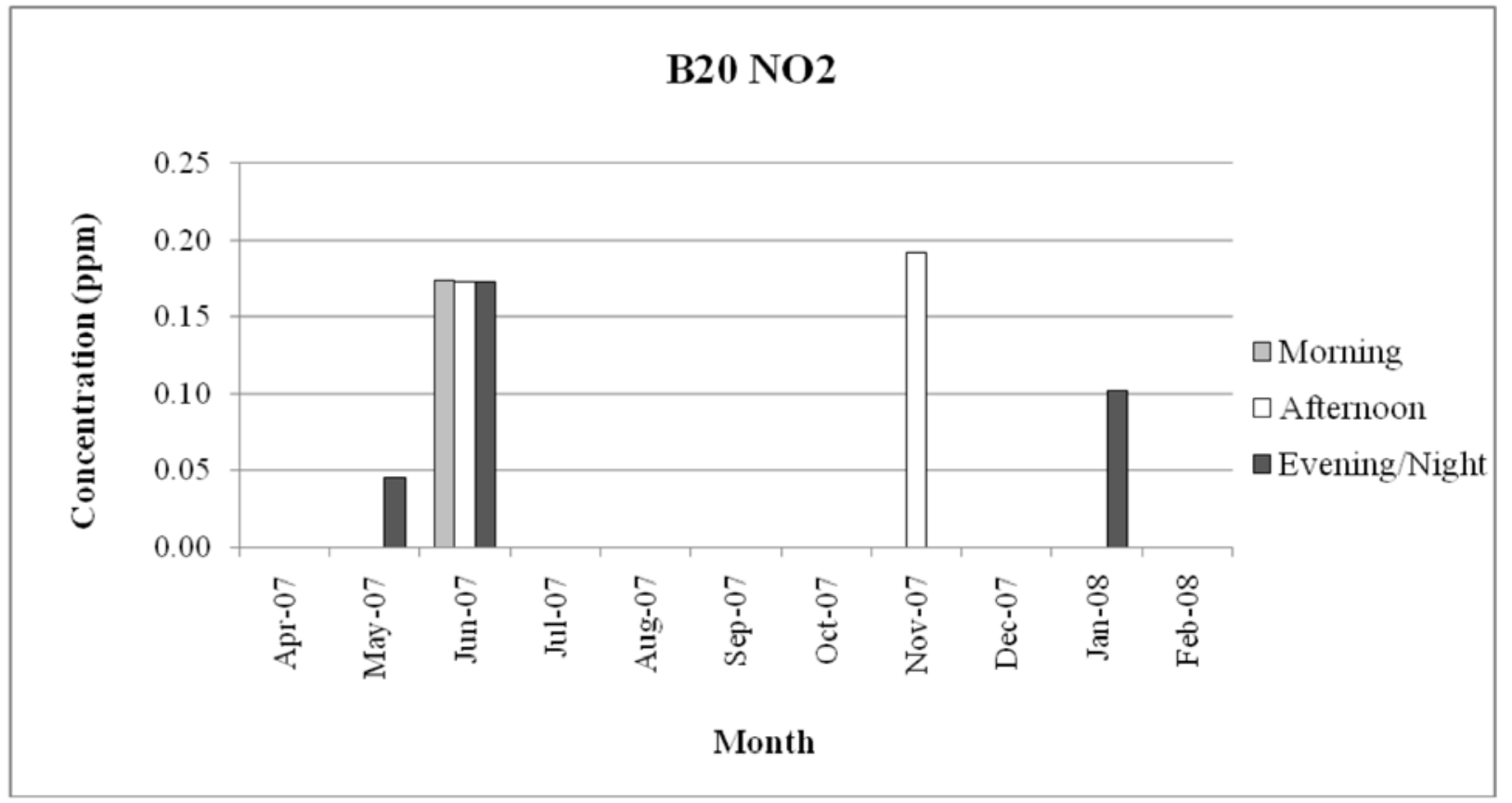

Fig. (13). TWA for $\mathrm{NO}_{2}$ in $\mathrm{B} 20$ bus.

both the test buses. The concentrations were well within the standard TWA limit of $3 \mathrm{ppm}$ for both the test buses. ANOVA test revealed that there is statistically no significant difference between occupant exposure levels to nitrogen dioxide in both $\mathrm{B} 20(\mathrm{P}=0.738)$ and ULSD buses $(\mathrm{P}=$ 0.628). Post hoc test for $\mathrm{NO}_{2}$ could not be performed due to lack of sufficient quality data to represent morning, afternoon, and evening/night. It can be observed that there is no representative sample for evening/night in ULSD bus and in a B20 bus there is at least one group (morning) that has fewer than 2 test cases.
Two sample $\mathrm{t}$ test performed for nitrogen dioxide in B20 and ULSD buses revealed that there is statistically no significant difference between the mean 8-hr TWA exposures $(\mathrm{T}=0.39, \mathrm{P}=0.724)$. Occupant exposure to nitrogen dioxide in a B20 bus $(\mu=0.13 \mathrm{ppm})$ is statistically similar to occupant exposure in ULSD bus $(\mu=0.09 \mathrm{ppm})$.

Fig. (15) shows the variation of nitrogen dioxide with vehicles during weekdays and weekends in the month of June in a B20 bus. From Fig. (15), one can observe vehicular traffic ahead to be mainly influencing nitrogen dioxide concentrations to for majority of the time. It can also be seen 


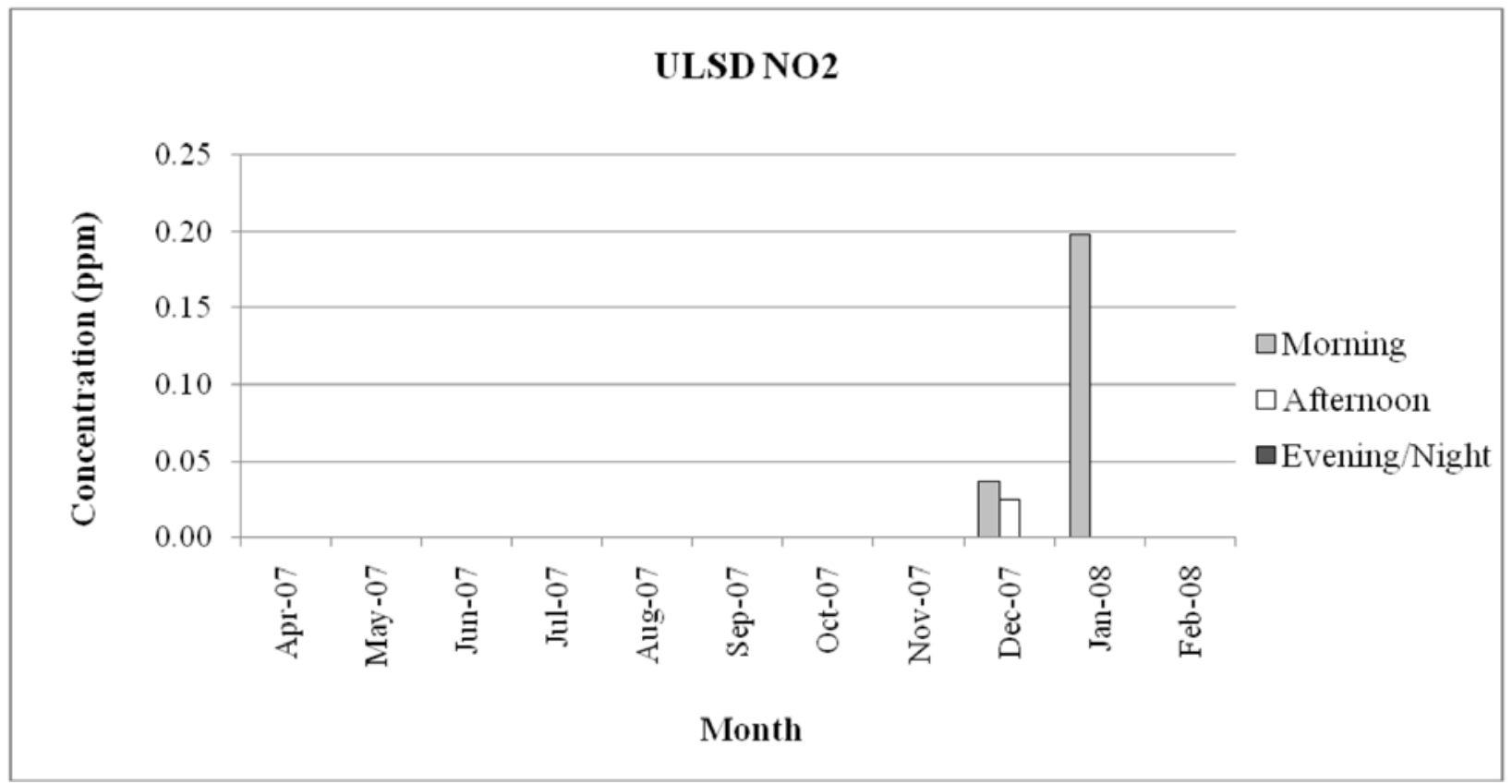

Fig. (14). TWA for $\mathrm{NO}_{2}$ in ULSD bus.

\section{NO2 Variation with Vehicular Traffic}

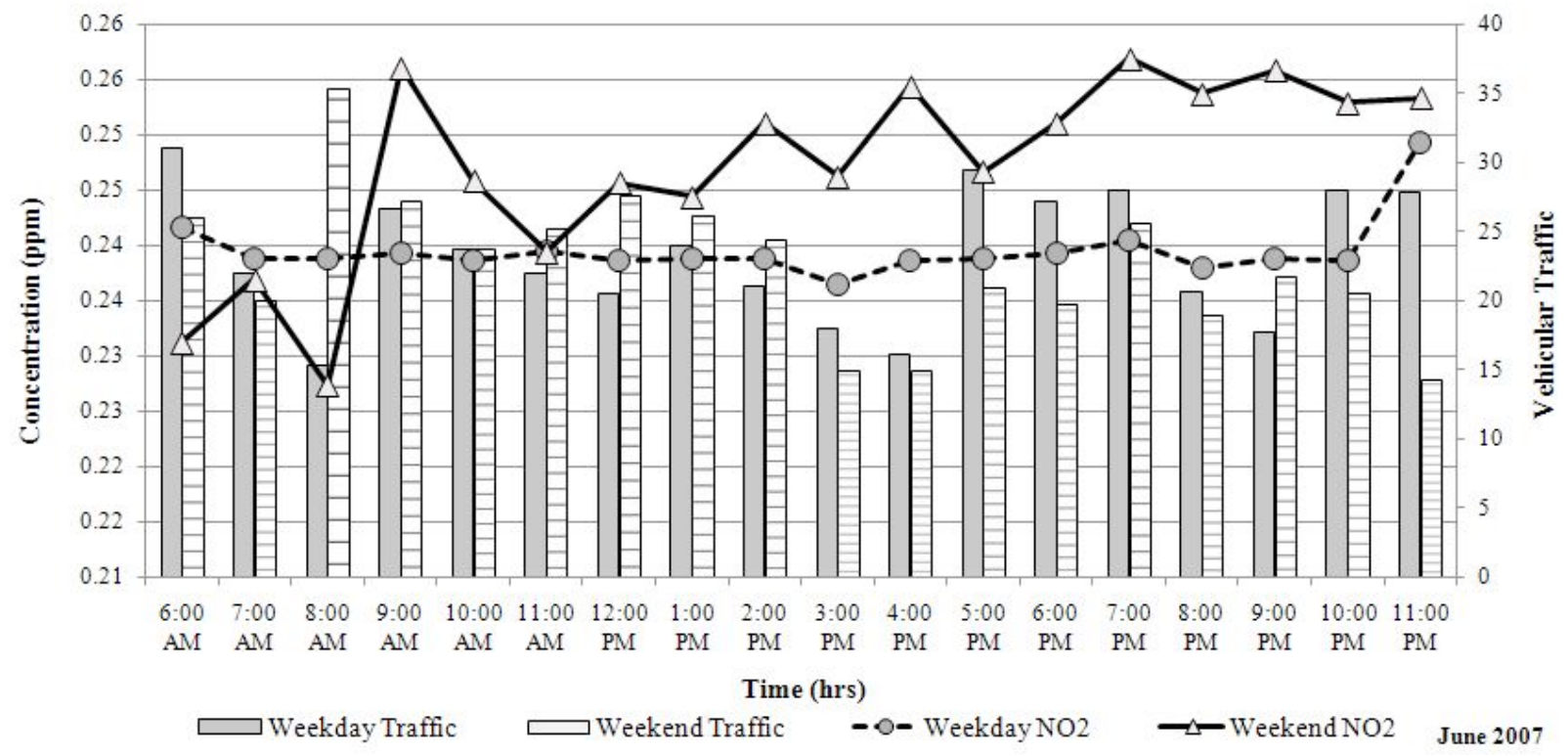

Fig. (15). $\mathrm{NO}_{2}$ concentration trend in a B20 bus.

from Fig. (15) that relatively higher $\mathrm{NO}_{2}$ levels were observed during weekends as compared to weekdays. This could be a result of higher penetration of nitrogen dioxide from lead vehicle (mainly trucks) exhaust, when more number of windows that were left open was observed to be higher during weekend as compared to weekday from the video analysis. $\mathrm{NO}_{2}$ levels varied with vehicular traffic and ventilation settings in both the test buses throughout the test period. Vijayan and Kumar [15] and Kadiyala and Kumar [17] observed vehicular traffic and ventilation settings to significantly affect vehicular nitrogen dioxide levels in both the buses.

\section{5. $\mathrm{SO}_{2}$ Concentration}

Figs. (16) and (17) present the occupant's exposure to $\mathrm{SO}_{2}$ during morning, afternoon, and evening/night time periods in biodiesel and ultra low sulfur diesel buses respectively. Occupants coming in the afternoon in both B20 and ULSD buses are the most affected by $\mathrm{SO}_{2}$ in respective buses. Occupants in ULSD bus are more exposed to sulfur dioxide as compared to those in a B20 bus as can be observed from Figs. (16) and (17). The concentrations were found to be well within the standard TWA limit of $2 \mathrm{ppm}$ in both the buses. On performing the ANOVA test, it was ob- 


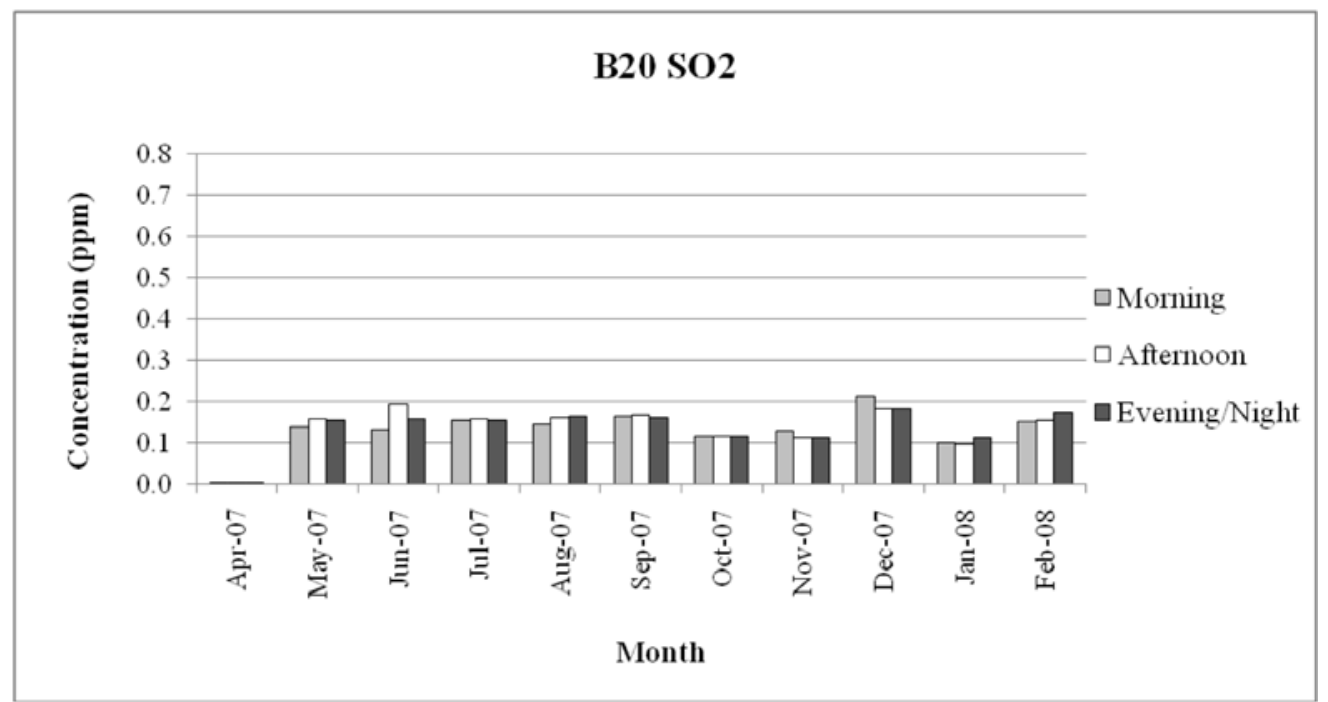

Fig. (16). TWA for $\mathrm{SO}_{2}$ in $\mathrm{B} 20$ bus.

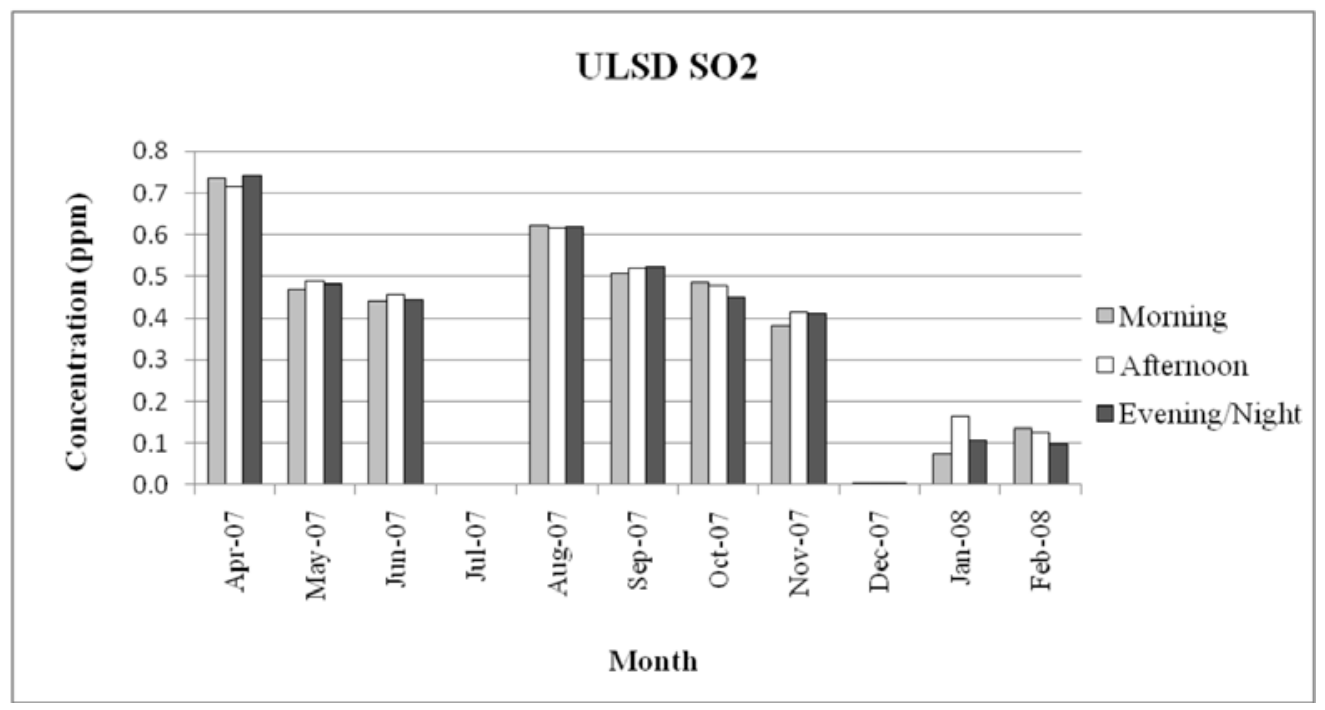

Fig. (17). TWA for $\mathrm{SO}_{2}$ in ULSD bus.

served that there is statistically no significant difference between exposure levels to sulfur dioxide in both B20 ( $\mathrm{P}=$ $0.973)$ and ULSD occupants $(\mathrm{P}=0.992)$. Table 8 presents a summary of the statistical significance of the difference in exposure to sulfur dioxide for occupants coming in during morning, afternoon, and evening/night in both B20 and ULSD with the post hoc test used being Tukey. From Table 8 , it can be observed that there is statistically no significant difference in occupant exposure to sulfur dioxide between any set of time periods in same bus (all p-values >0.05).

On performing the two sample t test, it was observed that there is a statistically significant difference between the mean 8-hr TWA exposure to sulfur dioxide in B20 and ULSD buses $(\mathrm{T}=-6.02, \mathrm{P}=0.000)$. Occupant exposure to sulfur dioxide in a B20 bus $(\mu=0.13 \mathrm{ppm})$ is significantly lower as compared to the occupant exposure in a ULSD bus $(\mu=0.39 \mathrm{ppm})$.

Fig. (18) shows the variation of sulfur dioxide with vehicles during weekdays and weekends in the month of June in a B20 bus. From Fig. (18), one can observe vehicular traffic ahead to be mainly influencing sulfur dioxide concentrations for majority of the time. It can also be seen from Fig. (18) that relatively higher $\mathrm{SO}_{2}$ levels were observed during weekends as compared to weekdays. This could be a result of higher penetration of $\mathrm{SO}_{2}$ from lead vehicle (mainly trucks) exhaust when more number of windows that were left open was observed to be higher during weekend as compared to weekday from the video analysis. Sulfur dioxide levels varied with vehicular traffic and ventilation settings in both the test buses throughout the test period. Kadiyala and Kumar [17] observed sulfur dioxide levels in both B20 and ULSD buses to be influenced by ventilation settings, vehicular traffic, and speed of the vehicle. Similar observations were made by Vijayan and Kumar [15].

\section{6. $\mathrm{PM}_{2.5}$ Concentration}

Figs. (19) and (20) show the occupant's exposure to particulate matter collected using Grimm Dust monitor in B20 and ULSD buses respectively. Occupants coming in during the morning are the most affected by exposure to particulate 
Table 8. ANOVA Results for Difference in $\mathrm{SO}_{2}$ Exposure Levels in $\mathrm{B} 20$ and ULSD Buses

\begin{tabular}{|c|c|c|c|c|c|}
\hline \multicolumn{2}{|c|}{ B20 Drivers } & \multirow{3}{*}{$\begin{array}{c}\mathbf{P}-\text { Value } \\
.974 \\
.981\end{array}$} & \multicolumn{2}{|c|}{ ULSD Drivers } & \multirow{2}{*}{$\begin{array}{c}\text { P - Value } \\
.974\end{array}$} \\
\hline & Afternoon $(\mu=0.136)$ & & & Afternoon $(\mu=0.398)$ & \\
\hline & Evening/Night $(\mu=0.135)$ & & & Evening/Night $(\mu=0.388)$ & .981 \\
\hline Afternoon $(\mu=0.136)$ & Evening/Night $(\mu=0.135)$ & .999 & Afternoon $(\mu=0.398)$ & Evening/Night $(\mu=0.388)$ & .999 \\
\hline
\end{tabular}

\section{SO2 Variation with Vehicular Traffic}

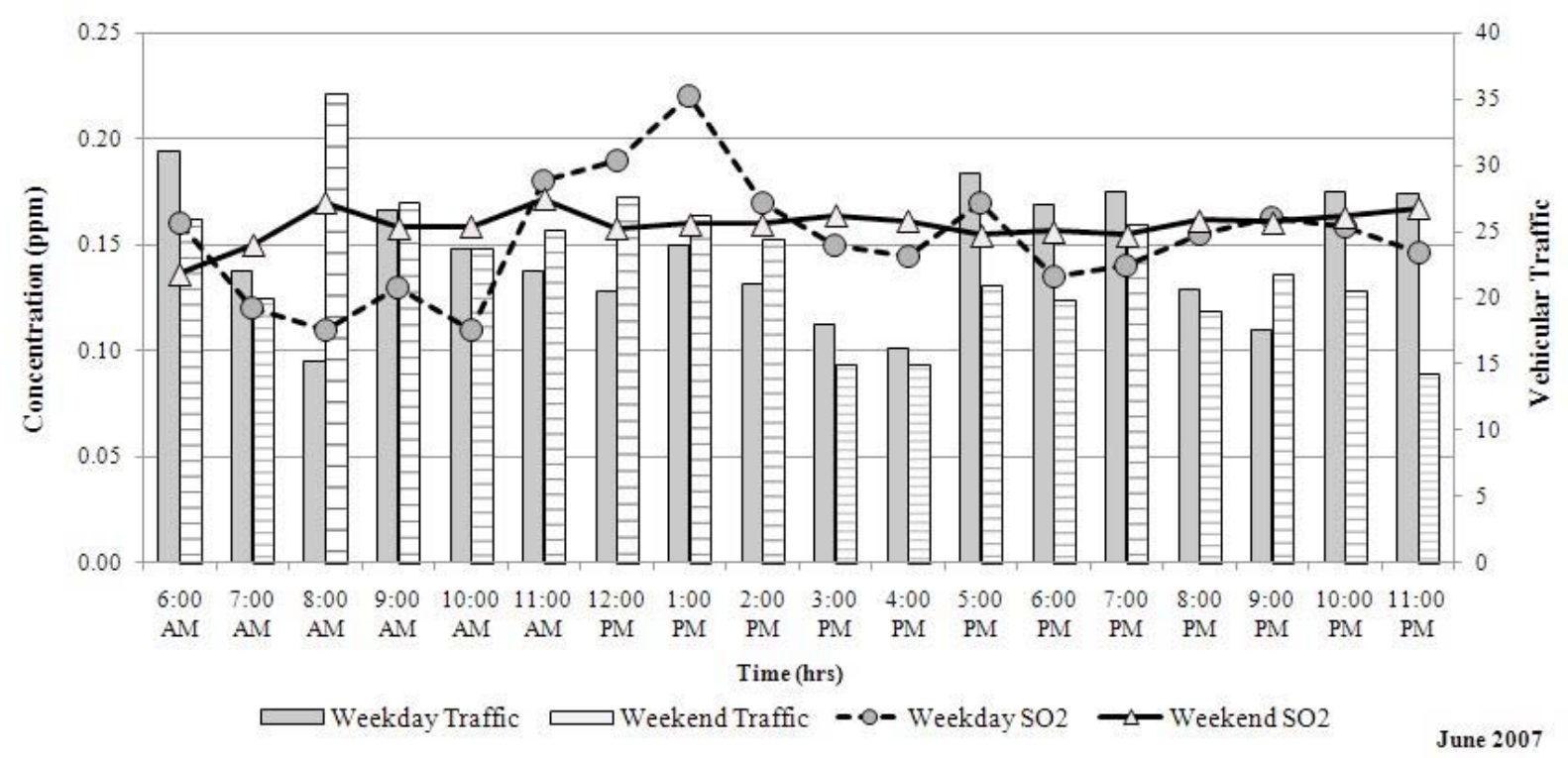

Fig. (18). $\mathrm{SO} 2$ concentration trend in a $\mathrm{B} 20$ bus.

matter in both the buses as can be observed from Figs. (19) and (20). This is mainly due to the fact that the test buses are in idle running condition inside the garage early in the morning along with many other buses that are also in idle running condition. The particulate matter levels never exceeded standard TWA limit of $35 \mu \mathrm{g} / \mathrm{m}^{3}$. ANOVA test indicated that there is statistically significant difference between occupant exposure levels to $\mathrm{PM}_{2.5}$ in both $\mathrm{B} 20(\mathrm{P}=0.029)$ and ULSD buses $(\mathrm{P}=0.014)$. Table 9 presents a summary of the statistical significance of the difference in occupant exposure to $\mathrm{PM}_{2.5}$ for morning, afternoon, and evening/night time periods in both B20 and ULSD with Tukey post hoc test. From Table 9 , it can be observed that there is statistically significant difference in occupant exposure to $\mathrm{PM}_{2.5}$ between morning and evening/night time periods of $\mathrm{B} 20$ bus $(\mathrm{P}=0.025)$ and not between the other two sets of time periods. Exposure of occupants coming in the morning in B20 bus $\left(\mu=16.58 \mu \mathrm{g} / \mathrm{m}^{3}\right)$ is statistically significantly exposed to higher levels of $\mathrm{PM}_{2.5}$ as compared to exposure of occupants coming in evening $/$ night of B20 bus $\left(\mu=9.35 \mu \mathrm{g} / \mathrm{m}^{3}\right)$. Similarly from Table 9, one can observe that there is statistically significant difference in exposure levels to $\mathrm{PM}_{2.5}$ between two sets of occupants coming in at different time periods in ULSD bus i.e. between morning and afternoon $(P=0.017)$, and morn- ing and evening/night $(\mathrm{P}=0.032)$. Occupant exposure to $\mathrm{PM}_{2.5}$ in the morning run of ULSD bus $\left(\mu=21.25 \mu \mathrm{g} / \mathrm{m}^{3}\right)$ is statistically significantly higher than the occupant exposure to $\mathrm{PM}_{2.5}$ in the afternoon $\left(\mu=9.55 \mu \mathrm{g} / \mathrm{m}^{3}\right)$ and evening $/$ night $\left(\mu=11.95 \mu \mathrm{g} / \mathrm{m}^{3}\right)$ time periods in same bus.

Two sample $\mathrm{t}$ test for $\mathrm{PM}_{2.5}$ in $\mathrm{B} 20$ and ULSD buses revealed that there is no statistically significant difference between the mean 8-hr TWA exposures $(\mathrm{T}=0.22, \mathrm{P}=0.831)$. Occupant exposure to $\mathrm{PM}_{2.5}$ in a B20 bus $\left(\mu=13.75 \mu \mathrm{g} / \mathrm{m}^{3}\right)$ is statistically similar to occupant exposure in a ULSD bus $\left(\mu=13.33 \mu \mathrm{g} / \mathrm{m}^{3}\right)$. Vijayan [14] and Kadiyala [18] observed that in-vehicle PM levels did not show any repetitive trends and were highly influenced by ambient PM concentrations. Shandilya and Kumar $[19,20]$ have provided details on chemical analysis of the particulate filter paper collected.

\section{CONCLUSION}

A methodology for obtaining in-vehicle pollutant concentrations continuously over longer period of time developed by Vijayan (2007) was adopted for this research and has been discussed. This protocol can be applied by engineers/environmentalists in the future to monitor indoor pollutants in vehicles continuously without having the burden to 


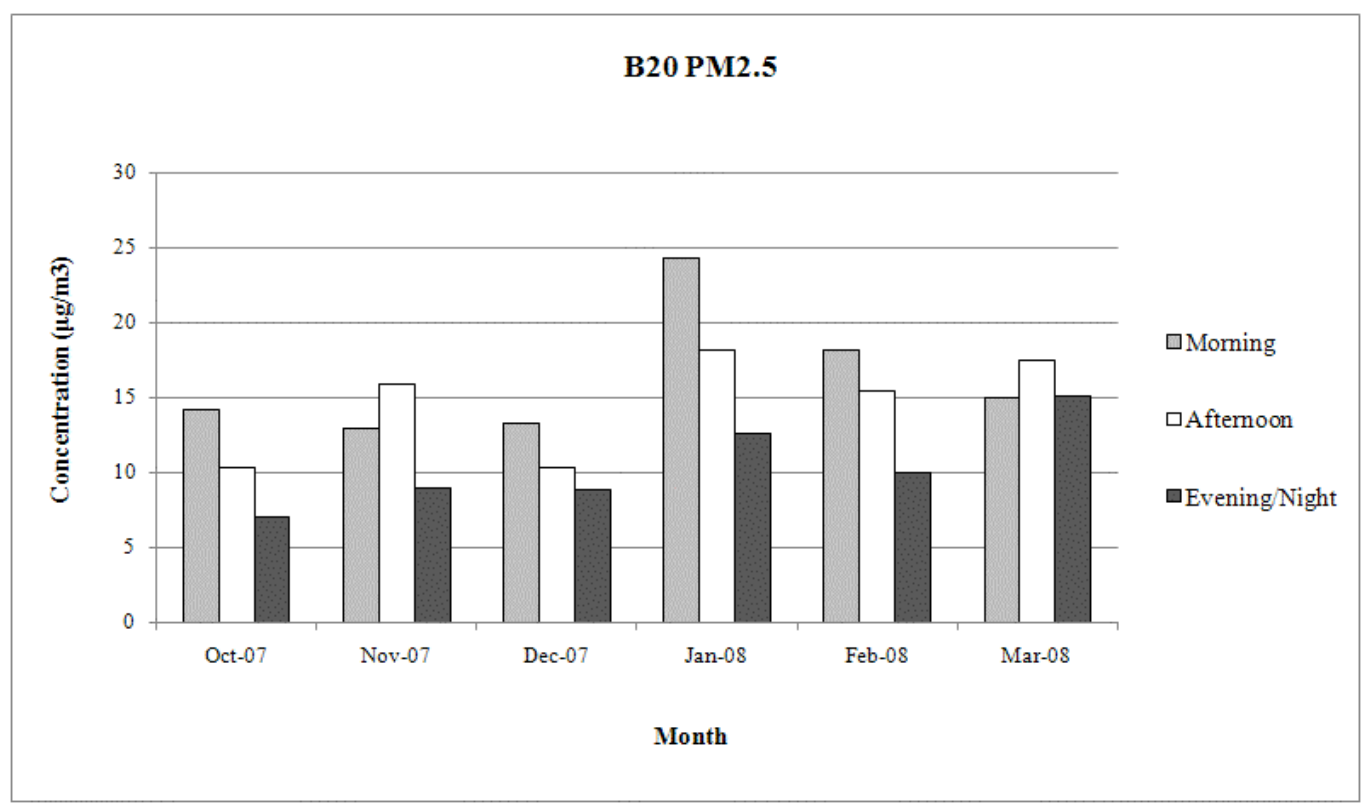

Fig. (19). TWA for $\mathrm{PM}_{2.5}$ in $\mathrm{B} 20$ bus.

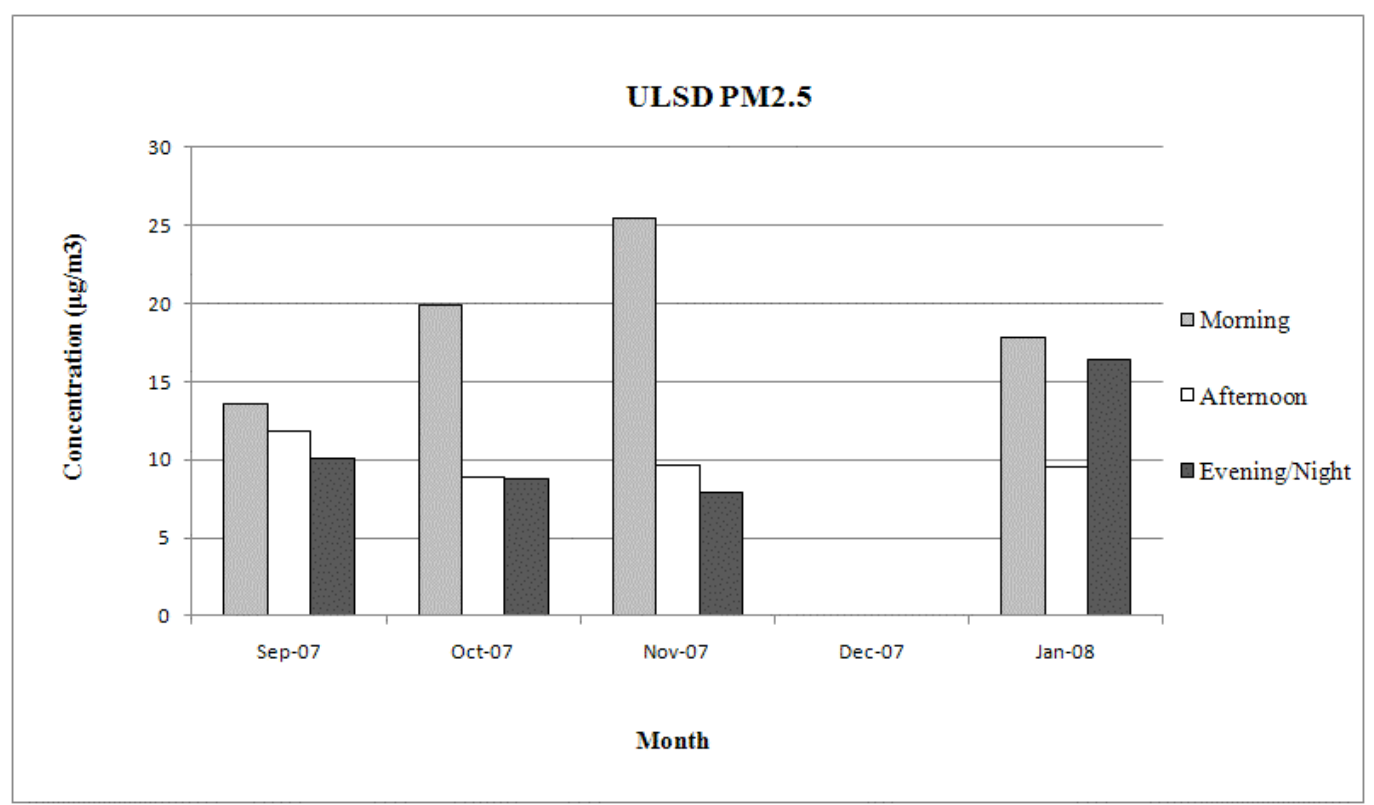

Fig. (20). TWA for $\mathrm{PM}_{2.5}$ in ULSD bus.

Table 9. ANOVA Results for Difference in $\mathbf{P M}_{2.5}$ Exposure Levels in $\mathbf{B 2 0}$ and ULSD Buses

\begin{tabular}{|l|c|c|c|c|}
\hline \multicolumn{2}{|c|}{ B20 Drivers } & P - Value & ULSD Drivers & P - Value \\
\hline \hline \multirow{2}{*}{ Morning $(\mu=16.58)$} & Afternoon $(\mu=13.29)$ & .524 & Morning $(\mu=21.25)$ & Afternoon $(\mu=9.55)$ \\
& Evening/Night $(\mu=9.35)$ &. $\mathbf{0 2 5}$ & & Evening/Night $(\mu=11.95)$ \\
\hline Afternoon $(\mu=13.29)$ & Evening/Night $(\mu=9.35)$ & .164 & Afternoon $(\mu=9.55)$ & Evening/Night $(\mu=11.95)$ \\
.837 \\
\hline
\end{tabular}

safeguard the instruments. The exposure study identified that none of the measured pollutants are problematic for the occupants except for carbon monoxide as they are only exposed to levels below the standard guidelines. B20 occupants are statistically significantly exposed to higher levels of car- bon monoxide and nitric oxide as compared to ULSD occupants, while ULSD occupants are more exposed to carbon dioxide and sulfur dioxide. Exposure to nitrogen dioxide and particulate matter are found not to be statistically significant between the two buses. Study of exposure to $\mathrm{CO}$, NO, and 
$\mathrm{SO}_{2}$ revealed that there is statistically no significant difference between the exposures for any set of occupants in both the buses coming in the morning, afternoon, and evening/night. There is statistically significant difference between exposure to carbon dioxide in a B20 bus and $\mathrm{PM}_{2.5}$ in both B20 and ULSD buses. It is recommended that the bus drivers be frequently rotated by transit authorities to ensure that particular group of drivers are not exposed to higher levels of in-vehicle pollutants during their service period. Since this study involves testing of only two buses, more research needs to be done to better understand the behavior of pollutants in transport microenvironments using biodiesel and ultra low sulfur diesel.

\section{ACKNOWLEDGEMENTS}

The authors would like to thank the United States Department of Transportation (US DOT) and Toledo Area Regional Transit Authority (TARTA) for the alternate fuel grant awarded to the Intermodal Transportation Institute (ITI) of the University of Toledo. The authors would also like to express their sincere gratitude to the TARTA management and the employees for their continued interest and involvement in this work. The views expressed in this paper are those of the authors alone and do not represent the views of the funding organizations.

\section{REFERENCES}

[1] N. E. Klepeis, W. C. Nelson, W. R. Ott, J. P. Robinson, A. M. Tsang, P. Switzer, J. V. Behar, S. C. Hern, and W. H. Engelmann, "The National Human Activity Pattern Survey (NHAPS): a resource for assessing exposure to environmental pollutants", Journal of Exposure Analysis and Environmental Epidemiology, vol. 11, pp. 231-252, February 2001.

[2] GS. Zhang, TT. Li, M. Luo, J. F. Liu, ZR. Liu, and YH. Bai, “Air pollution in the microenvironment of parked new cars", Building and Environment, vol. 43, pp. 315-319, March 2006.

[3] L. Y. Chan, W. L. Lau, S. C. Zou, Z. X. Cao, and S. C. Lai, "Exposure level of carbon monoxide and respirable suspended particulate in public transportation modes while commuting in urban area of Guangzhou, China", Atmospheric Environment, vol. 36, pp. 58315840, August 2002.

[4] L. Y. Chan, W. L. Lau, X. M. Wang, and J. H. Tang, "Preliminary measurements of aromatic VOCs in public transportation modes in Guangzhou, China", Environment International, vol. 29, pp. 429435, July 2003.

[5] E. Diapouli, G. Grivas, A. Chaloulakou, and N. Spyrellis, " $\mathrm{PM}_{10}$ and ultrafine particles counts in-vehicle and on-road in the Athens area", Water, Air, \& Soil Pollution: Focus, vol. 8, pp. 89-97, April 2007.

[6] L. Y. Chan, and Y. M. Liu, "Carbon monoxide levels in popular passenger commuting modes traversing major commuting routes in
Hong Kong", Atmospheric Environment, vol. 35, pp. 2637-2646, May 2001.

[7] J. Gulliver, and D. J. Briggs, "Personal exposure to particulate air pollution in transport microenvironments", Atmospheric Environment, vol. 38, pp. 1-8, January 2004.

[8] J. E. Gomez-Perales, R. N. Colvile, M. J. Nieuwenhuijsen, A. Fernandez-Bremauntz, V. J. Gutierrez-Avedoy, V. H. ParamoFigueroa, S. Blanco-Jimenez, E. Bueno-Lopez, F. Mandujano, R. Bernabe-Cabanillas, and E. Ortiz-Segovia, "Commuters' exposure to $\mathrm{PM}_{2.5}, \mathrm{CO}$, and benzene in public transport in the metropolitan area of Mexico City", Atmospheric Environment, vol. 38, pp. 12191229, March 2004

[9] AA. Fernandez-Bremauntz, and M. Ashmore, "Exposure of Commuters to carbon monoxide in Mexico City - 1. Measurement of invehicle concentrations", Atmospheric Environment, vol. 29, pp. 525-532, March 1995.

[10] M. J. Clifford, R. Clarke, and S. B. Riffat, "Driver's Exposure to carbon monoxide in Nottingham, UK", Atmospheric Environment, vol. 31, pp. 1003-1009, April 1997.

[11] L. Y. Chan, W. L. Lau, S. C. Lee, and C. Y. Chan, "Commuter exposure to particulate matter in public transportation modes in Hong Kong", Atmospheric Environment, vol. 36, pp. 3363-3373, July 2002 .

[12] H. W. Kuo, H. C. Wei, C. S. Liu, Y. Y. Lo, W. C. Wang, J. S. Lai, and C. C. Chan, "Exposure to volatile organic compounds while commuting in Taichung, Taiwan", Atmospheric Environment, vol. 34, pp. 3331-3336, August 1999.

[13] A. Chan, "Commuter exposure and indoor-outdoor relationships of carbon oxides in buses in Hong Kong", Atmospheric Environment, vol. 37, pp. 3809-3815, September 2003.

[14] A. Vijayan, "Characterization of vehicular exhaust emissions and IAQ of public transport buses on alternative fuels", PhD Dissertation, University of Toledo, Toledo, OH, USA, 2007.

[15] A. Vijayan, and A. Kumar, "Characterization of indoor air quality inside public transport buses using alternative diesel fuels", Paper \#08-2937 in Proceedings of TRB Conference, Transportation Research Board, Washington, D.C., 2008.

[16] Indoor Air Quality: Gases, vapors, particles and fibers, Available at http://ergo.human.cornell.edu/studentdownloads/DEA3500pdfs/iaq poll1.pdf [accessed July 2008].

[17] A. Kadiyala, and A. Kumar. "Study of in-vehicle pollutant behavior in public transport buses running on alternative fuels", Paper \# 571 in Proceedings of A\&WMA Annual Conference, Detroit, MI, 2009.

[18] A. Kadiyala, "Identification of factors affecting contaminant levels and determination of infiltration of ambient contaminants in public transport buses operating on biodiesel and ULSD fuels", Master's Thesis, University of Toledo, Toledo, OH, USA, 2008.

[19] K. K. Shandilya, and A. Kumar, "Qualitative evaluation of particulate matter inside public transit buses operated by biodiesel", The Open Environmental Engineering Journal, 2010; 3: 13-20.

[20] K. K. Shandilya, and A. Kumar, "Morphology of single inhalable particle inside public transit biodiesel fueled bus", Journal of Environmental Sciences, 2010; 22: 263-270.

(C) Kadiyala et al.; Licensee Bentham Open.

This is an open access article licensed under the terms of the Creative Commons Attribution Non-Commercial License (http://creativecommons.org/licenses/by-nc/3.0/g) which permits unrestricted, non-commercial use, distribution and reproduction in any medium, provided the work is properly cited. 